\title{
Modified Zeolite/Polysulfone Mixed Matrix Membrane for Enhanced $\mathrm{CO}_{2} / \mathrm{CH}_{4}$ Separation
}

\author{
Lanisha Devi Anbealagan 1,2, Tiffany Yit Siew Ng 1,2, Thiam Leng Chew 1,2,*id, Yin Fong Yeong ${ }^{1,2}$, \\ Siew Chun Low ${ }^{3}$, Yit Thai Ong ${ }^{4}$, Chii-Dong Ho ${ }^{5}$ (D) and Zeinab Abbas Jawad ${ }^{6}$ (D)
}

1 Department of Chemical Engineering, Faculty of Engineering, Universiti Teknologi PETRONAS, Seri Iskandar 32610, Perak, Malaysia; lanisha_19000945@utp.edu.my (L.D.A.); tiffany_921206@hotmail.com (T.Y.S.N.); yinfong.yeong@utp.edu.my (Y.F.Y.)

$2 \mathrm{CO}_{2}$ Research Center $\left(\mathrm{CO}_{2} \mathrm{RES}\right)$, Institute of Contaminant Management, Universiti Teknologi PETRONAS, Seri Iskandar 32610, Perak, Malaysia

3 School of Chemical Engineering, Engineering Campus, Universiti Sains Malaysia, Nibong Tebal 14300, Pulau Pinang, Malaysia; chsclow@usm.my

4 Department of Petrochemical Engineering, Faculty of Engineering and Green Technology, Universiti Tunku Abdul Rahman, Jalan Universiti, Bandar Barat, Kampar 31900, Perak, Malaysia; ongyt@utar.edu.my

5 Department of Chemical and Materials Engineering, Tamkang University, New Taipei City 25137, Taiwan; cdho@mail.tku.edu.tw

6 Department of Chemical Engineering, College of Engineering, Qatar University, Doha P.O. Box 2713, Qatar; zjawad@qu.edu.qa

* Correspondence: thiamleng.chew@utp.edu.my; Tel.: +60-5-368-7626

Citation: Anbealagan, L.D.; Ng, T.Y.S.; Chew, T.L.; Yeong, Y.F.; Low, S.C.; Ong, Y.T.; Ho, C.-D.; Jawad, Z.A. Modified Zeolite/Polysulfone Mixed Matrix Membrane for Enhanced $\mathrm{CO}_{2} / \mathrm{CH}_{4}$ Separation. Membranes 2021, 11, 630. https://doi.org/ 10.3390/membranes11080630

Academic Editor: Pei Sean Goh

Received: 19 June 2021

Accepted: 7 July 2021

Published: 16 August 2021

Publisher's Note: MDPI stays neutral with regard to jurisdictional claims in published maps and institutional affiliations.

Copyright: (C) 2021 by the authors Licensee MDPI, Basel, Switzerland. This article is an open access article distributed under the terms and conditions of the Creative Commons Attribution (CC BY) license (https:// creativecommons.org/licenses/by/ $4.0 /)$.
Abstract: In recent years, mixed matrix membranes (MMMs) have received worldwide attention for their potential to offer superior gas permeation and separation performance involving $\mathrm{CO}_{2}$ and $\mathrm{CH}_{4}$. However, fabricating defect-free MMMs still remains as a challenge where the incorporation of fillers into MMMs has usually led to some issues including formation of undesirable interfacial voids, which may jeopardize the gas separation performance of the MMMs. This current work investigated the incorporation of zeolite $\mathrm{RHO}$ and silane-modified zeolite $\mathrm{RHO}\left(\mathrm{NH}_{2}-\mathrm{RHO}\right)$ into polysulfone (PSf) based MMMs with the primary aim of enhancing the membrane's gas permeation and separation performance. The synthesized zeolite $\mathrm{RHO}, \mathrm{NH}_{2}-\mathrm{RHO}$, and fabricated membranes were characterized by X-ray diffraction (XRD) analysis, Fourier transform infrared-attenuated total reflection (FTIR-ATR), thermogravimetric analysis (TGA) and field emission scanning election microscopy (FESEM). The effects of zeolite loading in the MMMs on the $\mathrm{CO}_{2} / \mathrm{CH}_{4}$ separation performance were investigated. By incorporating $1 \mathrm{wt} \%$ of zeolite $\mathrm{RHO}$ into the MMMs, the $\mathrm{CO}_{2}$ permeability and ideal $\mathrm{CO}_{2} / \mathrm{CH}_{4}$ selectivity slightly increased by $4.2 \%$ and $2.7 \%$, respectively, compared to that of a pristine PSf membrane. On the other hand, a significant enhancement of $45 \%$ in ideal $\mathrm{CO}_{2} / \mathrm{CH}_{4}$ selectivity was attained by MMMs incorporated with $2 \mathrm{wt} \%$ of zeolite $\mathrm{NH}_{2}-\mathrm{RHO}$ compared to a pristine PSf membrane. Besides, all MMMs incorporated with zeolite $\mathrm{NH}_{2}-\mathrm{RHO}$ displayed higher ideal $\mathrm{CO}_{2} / \mathrm{CH}_{4}$ selectivity than that of the MMMs incorporated with zeolite RHO. By incorporating 1-3 wt\% zeolite $\mathrm{NH}_{2}$ - $\mathrm{RHO}$ into PSf matrix, MMMs without interfacial voids were successfully fabricated. Consequently, significant enhancement in ideal $\mathrm{CO}_{2} / \mathrm{CH}_{4}$ selectivity was enabled by the incorporation of zeolite $\mathrm{NH}_{2}-\mathrm{RHO}$ into MMMs.

Keywords: mixed matrix membranes (MMMs); polysulfone; zeolite RHO; silane modification; $\mathrm{CO}_{2}$ separation

\section{Introduction}

Carbon dioxide $\left(\mathrm{CO}_{2}\right)$ is commonly found in many industrial gas streams, such as natural gas stream and flue gas stream. $\mathrm{CO}_{2} / \mathrm{CH}_{4}$ and $\mathrm{CO}_{2} / \mathrm{N}_{2}$ separations are among the most important gas separation processes. This is because the presence of $\mathrm{CO}_{2}$ in the gas stream reduces the calorific value of the gas stream. In addition, $\mathrm{CO}_{2}$ makes the gas stream 
corrosive, which creates problems for the pipelines used for gas stream transportation. Membrane technology has received worldwide attention in the application of gas separation over the decades. This is due to the fact that membrane technology demonstrates advantages such as low energy consumption, compact design, simplicity of operation, flexibility of scale-up, possible use for continuous operation, and no requirement for phase change [1-3]. Polymeric membranes used to be very appealing in industrial gas separations due to its ease in scaling up and low fabrication cost. Nonetheless, these membranes commonly suffer an extremity in the tradeoff relation between permeability and selectivity [4]. Despite inorganic membranes offering advantages over polymeric membranes in terms of their high thermal stability, chemical resistance, and ability to offer relatively high gas permeability and selectivity, the application of inorganic membranes are restricted due to high fabrication cost and difficulty in fabricating defect-free membranes $[5,6]$. Hence, the development of mixed matrix membranes (MMMs) has been gaining increasing popularity among researchers in recent years.

As a promising new generation, MMMs are based on a system that combines two or more materials with excellent properties by embedding a dispersed inorganic filler into a continuous polymer matrix [1]. Relative to the current polymeric membranes, these MMMs offer a viable approach to achieve better gas permeability and selectivity, deriving from the incorporation of inorganic filler with inherent remarkable gas separation characteristics [7,8]. In this regard, zeolite filled MMMs appear to be a potential candidate for gas separation applications.

Zeolites are inorganic, microporous aluminosilicates that exhibit significant potential in gas separation due to their well-defined pore apertures and molecular sieving characteristics. The size selective characteristic of zeolite enables selective separation of smaller gas molecules from larger sized gas molecules $[9,10]$. Hence, this distinctive molecular sieving nature of zeolite can be favorable in enhancing the gas permeability and selectivity if it is incorporated into polymeric membranes. Zeolite RHO is receiving much attention for gas adsorption and separation as its framework has a $0.36 \mathrm{~nm}$ pore opening, which is in the vicinity of kinetic diameters of various gas molecules such as $\mathrm{CO}_{2}(0.33 \mathrm{~nm})$ and $\mathrm{CH}_{4}(0.38 \mathrm{~nm})$ [11]. In research reported by Atalay-Oral et al. [12], a high $\mathrm{CO}_{2}$ adsorption capacity of about $0.30 \mathrm{~g} / \mathrm{g}$ was attained for zeolite RHO. In addition, the ratios of $\mathrm{CO}_{2}$ adsorption capacity to $\mathrm{CH}_{4}$ adsorption capacity as high as 74.9 was reported for zeolite RHO [12]. This indicates the potential of zeolite $\mathrm{RHO}$ to be used for $\mathrm{CO}_{2} / \mathrm{CH}_{4}$ separation.

In spite of the fact that zeolite filled MMMs display numerous advantages in gas separation, these membranes have been experiencing issues related to the formation of nonselective interfacial voids due to poor compatibility between polymer matrix and inorganic fillers, causing adverse impact on the separation performance [13]. In order to improve the compatibility of zeolite in polymer matrix, surface modification of zeolite with silane coupling agents on the surface of zeolite has been proposed to enhance the polymer/zeolite compatibility $[14,15]$. Silane coupling agents such as ( $\gamma$-aminopropyl)-triethoxysilane (APTES), $N$ - $\beta$-(aminoethyl)- $\gamma$-aminopropyltrimethoxysilane (APTMS), $(\gamma$-aminopropyl)diethoxymethylsilane (APDEMS), and ( $\gamma$-glycidyloxy-propyl)-trimethoxysilane (GLYMO) consist of two reactive groups, namely an organic functional group and an inorganic hydrolysable group [16-19]. R- $\left(\mathrm{CH}_{2}\right)_{\mathrm{n}}-\mathrm{Si}-\mathrm{X}_{4-\mathrm{n}}$ is the general formula of a silane coupling agent, wherein $R$ is the organic functional group such as amine, methacryloxy, or epoxy group, whilst $X$ acts as the methoxy, ethoxy, or acetoxy in hydrolysable group [14]. By hydrolyzing the coupling agents, free silanol groups $\left(\mathrm{Si}(\mathrm{OH})_{4-n}\right)$ will be formed and will be able to react with hydroxyl groups on the external surface of zeolites via hydrogen bonding. The amine group acts as an active site and creates a hydrophobic bond at the interface between zeolite and polymer chain so as to promote adhesion between zeolite and polymer matrix [20-22]. In fact, the distinctive properties of silane coupling agents may not only alter the surface properties of zeolite from hydrophilic to hydrophobic, but also enhance zeolite affinity for the polymer matrix [23-25]. 
Amooghin et al. [15] investigated the effect of silane modification on Matrimid 5218/NaY MMMs with APDEMS for $\mathrm{CO}_{2} / \mathrm{CH}_{4}$ separation. It was clearly demonstrated that the polymer/zeolite interfacial adhesion was enhanced by silane-modified zeolite $\mathrm{NaY}$ particles and the particles were well distributed up to $15 \mathrm{wt} \%$ within the Matrimid matrix without any agglomeration. There was about a $16 \%$ increase in $\mathrm{CO}_{2}$ permeability from 8.34 Barrer for Matrimid membrane to 9.70 Barrer for MMMs incorporated with $15 \mathrm{wt} \%$ silanated $\mathrm{NaY}$. The respective $\mathrm{CO}_{2} / \mathrm{CH}_{4}$ selectivity was also increased by approximately 57\% from 36.3 to 57.1 [15]. Perchar et al. [26] used APTMS-modified ZSM-2 to prepare polyimide MMMs. Absence of voids between polymer and modified zeolite was revealed in SEM and TEM studies and modified zeolites were well distributed across the polymer surface [26]. In another work, Perchar et al. [27] further incorporated APTES-modified zeolite L into polyimide membranes. There was no interfacial voids between polyimide and modified zeolite L in observed SEM images, suggesting high affinity was established between polyimide and modified zeolite L [27]. In the preparation of polysulfone (PSf) MMMs, Junaidi et al. [14] modified SAPO-34 zeolite using APTMS in isopropanol and ethanol, respectively. Apart from reduction of filler agglomeration, it was proved that APTMS as silane coupling agent was able to reduce interfacial voids in $M M M s . \mathrm{CO}_{2}$ permeance of $706 \mathrm{GPU}$ and $\mathrm{CO}_{2} / \mathrm{CH}_{4}$ selectivity of 31 were achieved by PSf/SAPO-34 MMMs with APTMS-modified SAPO-34 in ethanol [14]. Ismail et al. [28] fabricated polyethersulfone (PES) MMMs using APTES-modified zeolite 4A. Moreover, good compatibility between PES and silanated zeolite was noticed. A PES membrane incorporated with $20 \mathrm{wt} \%$ modified zeolite $4 \mathrm{~A}$ yielded significant selectivity enhancement from 28.75 to 46.28 in $\mathrm{CO}_{2} / \mathrm{CH}_{4}$ separation.

To the best of our knowledge, there is no literature reported on the silane-modified zeolite RHO incorporated as filler to develop MMMs for $\mathrm{CO}_{2} / \mathrm{CH}_{4}$ separation. In this work, zeolite RHO was chosen as the filler in polysulfone (PSf) matrix to develop MMMs. $\mathrm{CO}_{2} / \mathrm{CH}_{4}$ permeation and separation studies were performed on the fabricated MMMs, because zeolite $\mathrm{RHO}$ has a $0.36 \mathrm{~nm}$ pore opening, which is between the kinetic diameter of $\mathrm{CO}_{2}(0.33 \mathrm{~nm})$ and $\mathrm{CH}_{4}(0.38 \mathrm{~nm})$ [11]. This work focused on an investigation of the effect of filler loading on the properties and $\mathrm{CO}_{2} / \mathrm{CH}_{4}$ separation performance of the MMMs. In addition, (3-aminopropyl)-triethoxysilane (APTES) was adopted as a silane coupling agent for surface modification of zeolite RHO. MMMs incorporated with APTESmodified zeolite $\mathrm{RHO}$ were also developed to investigate the enhancement in $\mathrm{CO}_{2} / \mathrm{CH}_{4}$ separation performance as well as in the properties of the MMMs. The obtained evaluation information from this work could serve as good indicator of the MMMs performance when the MMMs are to be applied in real-life industrial applications in gas processing.

\section{Materials and Methods}

\subsection{Materials}

Polysulfone (PSf) pellets (average $\mathrm{M}_{\mathrm{n}} \sim 16,000$, average $\mathrm{M}_{\mathrm{w}} \sim 35,000$, Sigma Aldrich, St. Louis, MO, USA) were used to fabricate pristine PSf membranes and their respective MMMs. Colloidal silica LUDOX HS-40 (40 wt \%, Sigma Aldrich, St. Louis, MO, USA), cesium hydroxide ( $50 \mathrm{wt} \%$ aqueous solution, Sigma Aldrich), sodium aluminate (53 wt $\%$ $\mathrm{Al}_{2} \mathrm{O}_{3}, 47 \mathrm{wt} \% \mathrm{Na}_{2} \mathrm{O}$, Sigma Aldrich, St. Louis, MO, USA), sodium hydroxide ( $>98 \%$, Fisher Scientific, Hampton, NH, USA), and deionized water were used to synthesize zeolite RHO. (3-aminopropyl)-triethoxysilane (APTES) (99\%) was acquired from Sigma Aldrich (St. Louis, MO, USA) and used without further purification. Tetrahydrofuran (THF) $(>99.8 \%)$, toluene $(>99.9 \%)$, and ethanol $(>99.9 \%)$ were supplied by Merck Co (Kenilworth, NJ, USA). and employed without further purification. $\mathrm{CO}_{2}$ and $\mathrm{CH}_{4}$ gases ( $>99.5 \%$ purity) were provided by Air Products (Detroit, MI, USA).

\subsection{Zeolite RHO Synthesis}

Zeolite RHO was synthesized by following the method reported in our previous work [29]. A precursor solution with molar composition of $3 \mathrm{Na}_{2} \mathrm{O}: 0.4 \mathrm{Cs}_{2} \mathrm{O}: \mathrm{Al}_{2} \mathrm{O}_{3}: 10.8$ 
$\mathrm{SiO}_{2}: 110 \mathrm{H}_{2} \mathrm{O}$ was prepared by dissolving sodium hydroxide in deionized water at room temperature. Then, cesium hydroxide and sodium aluminate were added to the mixture consecutively. After complete dissolution, colloidal silica was added to the solution under stirring for $30 \mathrm{~min}$. The resultant precursor solution was further pretreated with $40 \mathrm{kHz}$ of ultrasonic irradiation for $120 \mathrm{~min}$ in an ultrasonic bath (Sonica 2400 EP S3, Milan, Italy). The precursor solution was stirred for aging at room temperature for $24 \mathrm{~h}$. The aged solution was then transferred into a stainless steel autoclave reactor for hydrothermal synthesis for 2 days at $100{ }^{\circ} \mathrm{C}$. Upon completion of hydrothermal synthesis, the synthesized zeolite RHO were obtained via repeated centrifugation and rinsing with deionized water. The zeolite $\mathrm{RHO}$ was then dried in an oven at $80^{\circ} \mathrm{C}$ overnight.

\subsection{Silane Modification of Zeolite RHO}

Zeolite RHO sample was dried overnight in oven at $80^{\circ} \mathrm{C}$ before being used. The silane modification procedure was carried out by following Plueddemann's method with modifications [25]. A total of $2 \mathrm{~g}$ of zeolite RHO powder was dispersed in $50 \mathrm{~mL}$ of toluene and stirred for one hour at room temperature. Then, $4 \mathrm{~mL}$ of APTES was added dropwise to the mixture and it was refluxed at $110^{\circ} \mathrm{C}$ for $4 \mathrm{~h}$. After $4 \mathrm{~h}$, the mixture was left to cool to room temperature, followed by filtration and washing with toluene and ethanol to remove unreacted silane. The modified zeolite RHO was dried in the oven at $80^{\circ} \mathrm{C}$ overnight.

\subsection{Mixed Matrix Membrane Fabrication}

PSf pellets, zeolite $\mathrm{RHO}$, and silane-modified zeolite $\mathrm{RHO}\left(\mathrm{NH}_{2}-\mathrm{RHO}\right)$ powder were pre-dried at $110^{\circ} \mathrm{C}$ and $80^{\circ} \mathrm{C}$ overnight, respectively, to remove moisture content. Priming method was used to fabricate the MMMs to minimize agglomeration of inorganic fillers [30]. Table 1 shows the sample names of pristine membranes and MMMs fabricated in the current study. Different loading of zeolite $\mathrm{RHO}$ and $\mathrm{NH}_{2}-\mathrm{RHO}$, as described in Table 1, were added, to the THF solvent and ultrasonicated for $30 \mathrm{~min}$ to yield a homogenous particle dispersion. Then, priming was carried out by the addition of $10 \%$ of total amount of PSf pellets into the dope solution and stirred for $4 \mathrm{~h}$ to ensure PSf was effectively coated around zeolite particles [31]. The remaining PSf pellets were added in batches to form the final dope solution, which was further stirred overnight at room temperature. Prior to casting, the dope solution was degassed in an ultrasonic bath for $30 \mathrm{~min}$ to eliminate trapped microbubbles. The resultant dope solution was poured and cast on a cleaned flat levelled glass plate with a $0.2 \mathrm{~mm}$ gap of casting knife. The cast membrane layer on the glass plate was dried for $24 \mathrm{~h}$ at ambient pressure and temperature. Then, the membrane layer was detached from the glass plate and dried overnight in an oven at $75{ }^{\circ} \mathrm{C}$ to remove any residual solvent. For comparison purposes, a pristine PSf membrane was also fabricated by preparing a polymeric dope solution composed of $27 \mathrm{wt} \% \mathrm{PSf}$ pellets in THF solvent. Lastly, the fabricated membranes were kept in a vacuum desiccator.

Table 1. The pristine membrane and MMMs fabricated in current study.

\begin{tabular}{ccc}
\hline Filler Loading in PSf (wt $\%)$ & MMMs with Zeolite RHO & $\begin{array}{c}\text { MMMs with Silane-Modified } \\
\text { Zeolite RHO }\end{array}$ \\
\hline 0 & Pristine PSf & Pristine PSf \\
1 & $1 \mathrm{RHO} / \mathrm{PSf}$ & $1 \mathrm{NH}_{2}-\mathrm{RHO} / \mathrm{PSf}$ \\
2 & $2 \mathrm{RHO} / \mathrm{PSf}$ & $2 \mathrm{NH}_{2}-\mathrm{RHO} / \mathrm{PSf}$ \\
3 & $3 \mathrm{RHO} / \mathrm{PSf}$ & $3 \mathrm{NH}_{2}-\mathrm{RHO} / \mathrm{PSf}$ \\
4 & $4 \mathrm{RHO} / \mathrm{PSf}$ & $4 \mathrm{NH}_{2}-\mathrm{RHO} / \mathrm{PSf}$ \\
5 & $5 \mathrm{RHO} / \mathrm{PSf}$ & $5 \mathrm{NH}_{2}-\mathrm{RHO} / \mathrm{PSf}$ \\
\hline
\end{tabular}

\subsection{Zeolite and Membrane Samples Characterization}

X-ray diffraction (XRD) analysis was conducted on the zeolite and membrane samples via diffractometer ( $X^{\prime}$ Pert ${ }^{3}$ Powder \& Empyrean, PANalytical, Malvern, UK) with monochromatic $\mathrm{CuK} \alpha$ radiation at a wavelength of $0.154 \mathrm{~nm}$, accelerating voltage of $40 \mathrm{kV}$ 
and current of $40 \mathrm{~mA}$. Fourier transform infrared-attenuated total reflection (FTIR-ATR) was performed using a spectrometer (Perkin Elmer, Frontier, Waltham, MA, USA) to identify the functional groups present in the zeolite and membrane samples. The cross-sectional images of the membrane samples were monitored by field emission scanning electron microscopy (FESEM) (Zeiss Supra 55VP, Jena, Germany). All membrane samples were fractured in liquid nitrogen and sputter-coated with gold. The samples were mounted on stainless-steel holders and observed at an accelerating voltage of $10 \mathrm{kV}$ in high vacuum conditions. Thermogravimetric analysis (TGA) was employed to evaluate the thermal stability of the zeolite and membrane samples using an analyzer (Perkin Elmer, STA 6000, Waltham, MA, USA). The samples were subjected to heating at a heating rate of $10^{\circ} \mathrm{C} / \mathrm{min}$ under nitrogen atmosphere.

\subsection{Gas Permeation and Separation Evaluation}

The gas permeation and separation evaluation were carried out for pristine PSf membrane and MMMs with different filler loadings using the experimental setup as shown in Figure 1. The membrane sample was sealed in a flat sheet membrane module with a silicon gasket to prevent gas leakage. Single $\mathrm{CO}_{2}$ or $\mathrm{CH}_{4}$ gas was fed separately to the membrane sample in the membrane module. The gas permeation was conducted at $25^{\circ} \mathrm{C}$, where transmembrane pressure was regulated at 4 bar using back pressure regulator while the permeate pressure was kept at atmospheric pressure. Capillary bubble flowmeter was employed to measure the volumetric flow rate of the permeate. The $\mathrm{CO}_{2}$ and $\mathrm{CH}_{4}$ gas permeability were calculated with the following Equation (1):

$$
P=\frac{Q l}{A \Delta P}
$$

where $P$ is the gas permeability across the membrane in Barrer (1 Barrer $=1 \times 10^{-10} \mathrm{~cm}^{3}$ (STP) $\left.\mathrm{cm} / \mathrm{cm}^{2} \mathrm{~s} \mathrm{cmHg}\right), Q$ is gas flux $\left(\mathrm{cm}^{3} \mathrm{STP} / \mathrm{s}\right), l$ is membrane thickness $(\mathrm{cm}), A$ is effective membrane area $\left(\mathrm{cm}^{2}\right)$ and $\Delta P$ is transmembrane pressure $(\mathrm{cmHg})$ across the membrane. The ideal selectivity of the membrane was calculated as the ratio of $\mathrm{CO}_{2}$ permeability to $\mathrm{CH}_{4}$ permeability by using Equation (2):

$$
\alpha_{\mathrm{CO}_{2} / \mathrm{CH}_{4}}=\frac{P_{A}}{P_{B}}
$$

where $P_{A}$ and $P_{B}$ are the $\mathrm{CO}_{2}$ and $\mathrm{CH}_{4}$ permeability, respectively. The gas permeation measurement of each single gas was repeated three successive times.

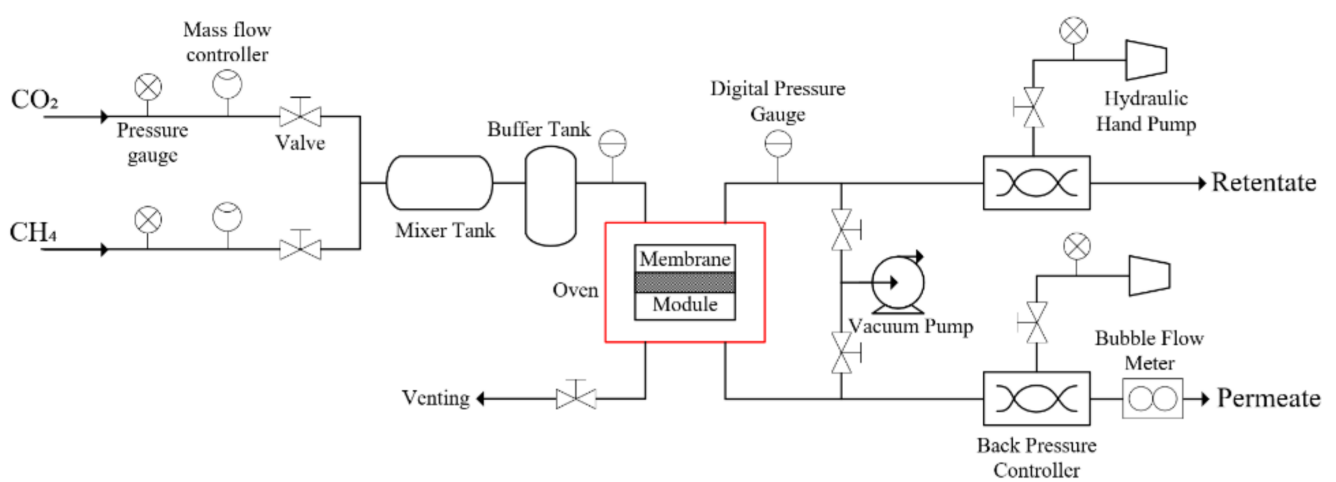

Figure 1. Schematic of the experimental setup used for gas permeation and separation studies. 


\section{Results}

\subsection{Crystallographic Analysis}

\subsubsection{Comparison of Zeolite $\mathrm{RHO}$ and $\mathrm{NH}_{2}-\mathrm{RHO}$}

The crystallographic of zeolite $\mathrm{RHO}$ and $\mathrm{NH}_{2}-\mathrm{RHO}$ were ascertained by XRD analysis, as illustrated in Figure 2. As shown in Figure 2a, the synthesized zeolite RHO possessed characteristic diffraction peaks with respective $2 \theta$ angles at about $8.3^{\circ}, 16.6^{\circ}, 18.6^{\circ}, 25.1^{\circ}$, $26.4^{\circ}, 30.2^{\circ}, 32.5^{\circ}$, and $35.7^{\circ}$, which is in agreement with the XRD patterns reported by Liu et al. [32]. According to Kim and Lee [33], sharp diffraction peaks with high intensity symbolize a highly crystalline region present in a synthesized sample. Zeolite $\mathrm{NH}_{2}-\mathrm{RHO}$ also portrayed similar sharp diffraction peaks to that of zeolite RHO as displayed in Figure $2 b$, which indicates a high degree of crystallographic regularity in the synthesized zeolite $\mathrm{NH}_{2}-\mathrm{RHO}$. However, the characteristic peak intensity of zeolite $\mathrm{NH}_{2}-\mathrm{RHO}$ was slightly reduced compared to pure zeolite RHO. This situation can be explained by the incorporation of silane modification to the zeolite RHO surface where APTES slightly disrupted the crystalline structure of zeolite $\mathrm{NH}_{2}-\mathrm{RHO}$, causing in a slight decrement of crystallinity [34].

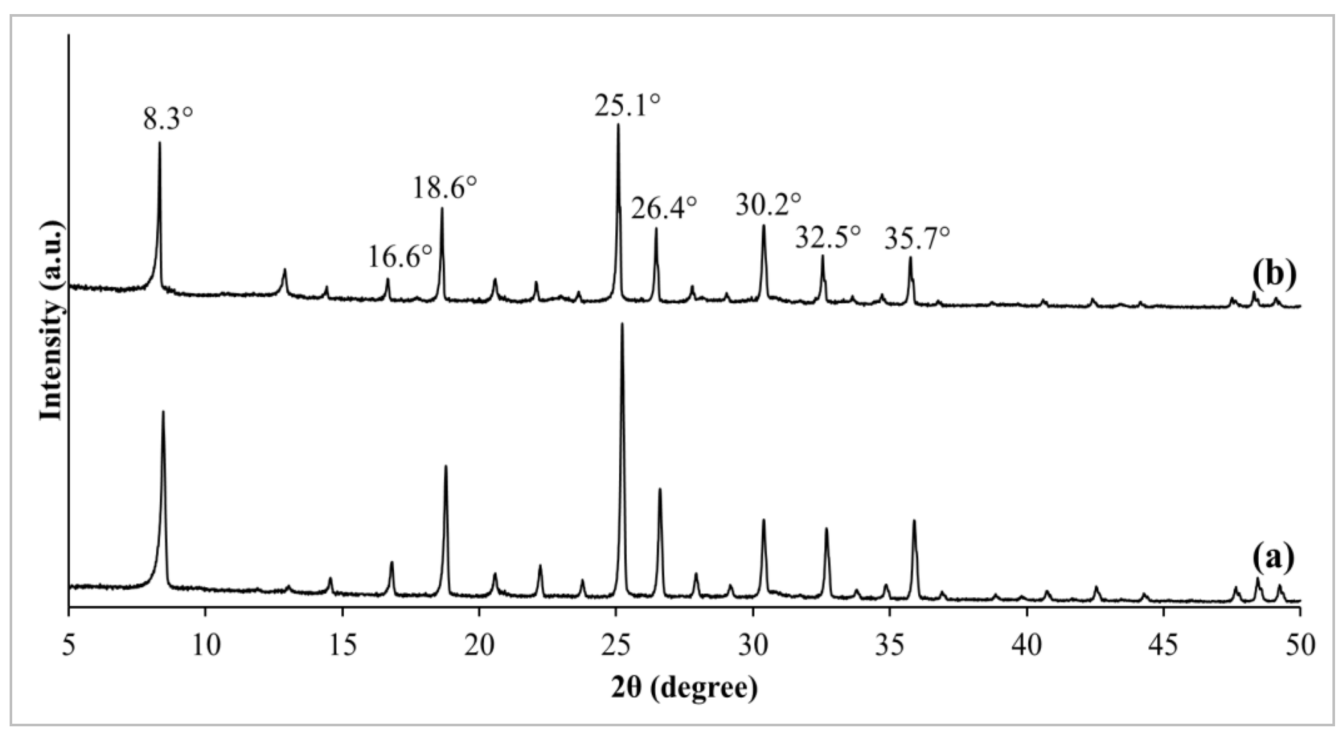

Figure 2. XRD patterns of (a) zeolite RHO and (b) zeolite $\mathrm{NH}_{2}-\mathrm{RHO}$.

\subsubsection{Comparison of Pristine PSf Membrane and MMMs}

The changes in crystallographic of pristine PSf membrane and fabricated MMMs were further analyzed and visualized in Figures 3 and 4. Firstly, pristine PSf manifested amorphous polymer structure by revealing a broad, low intensity peak at a $2 \theta$ angle of about $18^{\circ}$ [35]. Upon addition of zeolite $\mathrm{RHO}$ and $\mathrm{NH}_{2}-\mathrm{RHO}$ into PSf matrix, several additional sharp characteristic peaks with $2 \theta$ angles at about $8.3^{\circ}, 25.1^{\circ}$, and $30.2^{\circ}$ were observed in the MMMs, which indicates the presence of zeolite $\mathrm{RHO}$ and $\mathrm{NH}_{2}-\mathrm{RHO}$ in the MMMs. As the loading of zeolite $\mathrm{RHO}$ and $\mathrm{NH}_{2}-\mathrm{RHO}$ increased from $1 \mathrm{wt} \%$ to $5 \mathrm{wt} \%$, the peak intensities at respective $2 \theta$ angles for zeolite $\mathrm{RHO}$ and $\mathrm{NH}_{2}-\mathrm{RHO}$ also increased. A similar phenomenon was reported by Ahmad et al. [36] when increasing peak intensity of zeolite $4 \mathrm{~A}$ was observed in the Matrimid based MMMs as the loading of zeolite $4 \mathrm{~A}$ increased from $10 \mathrm{wt} \%$ to $30 \mathrm{wt} \%$. 


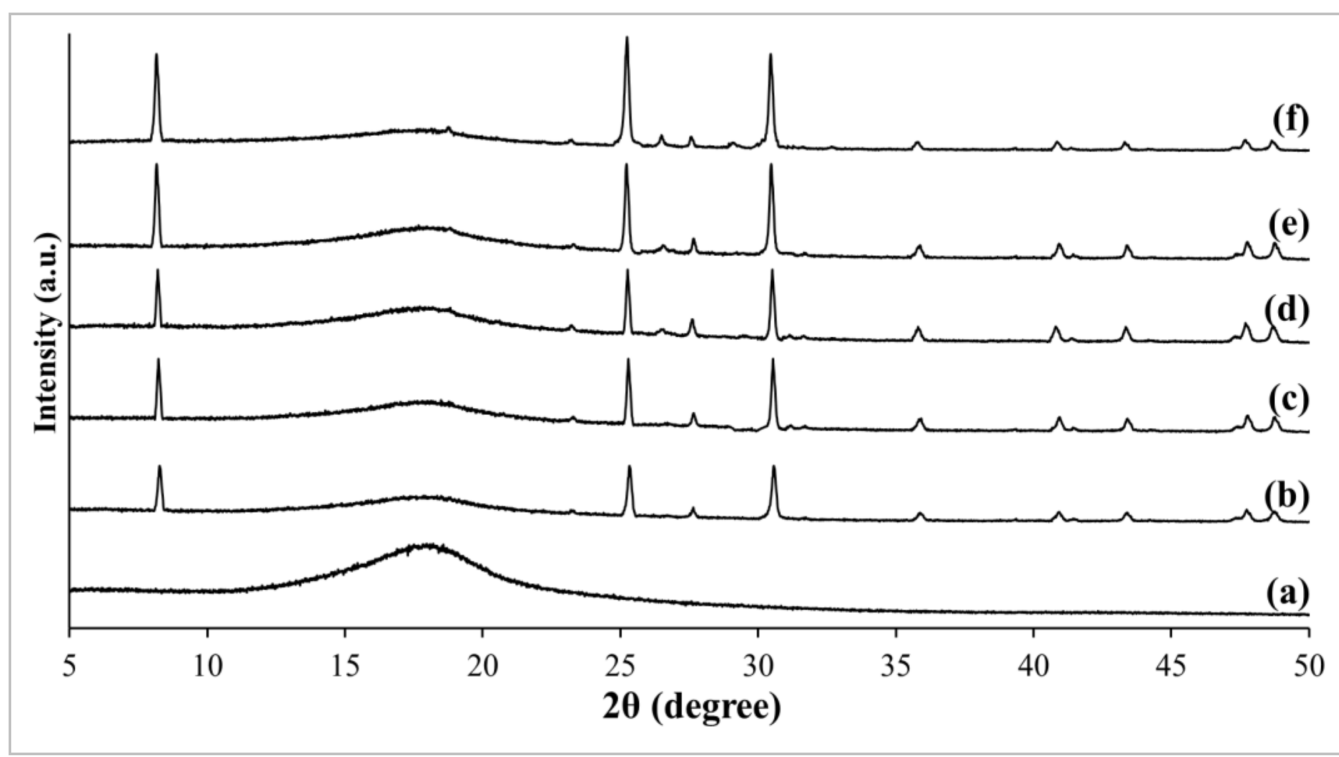

Figure 3. XRD patterns of (a) pristine PSf membrane, (b) 1RHO/PSf, (c) 2RHO/PSf, (d) 3RHO/PSf, (e) $4 \mathrm{RHO} / \mathrm{PSf}$, and (f) $5 \mathrm{RHO} / \mathrm{PSf}$ MMMs.

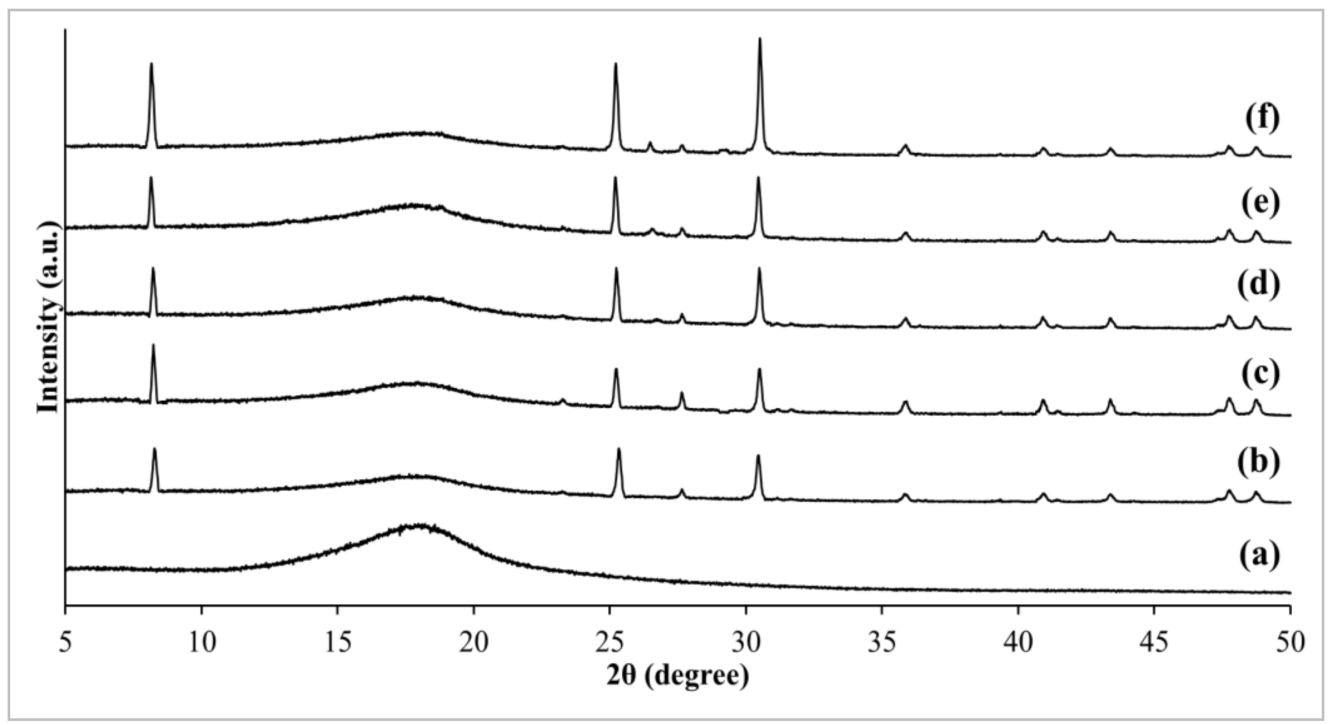

Figure 4. XRD patterns of (a) pristine PSf membrane, (b) $1 \mathrm{NH}_{2}-\mathrm{RHO} / \mathrm{PSf}$, (c) $2 \mathrm{NH}_{2}-\mathrm{RHO} / \mathrm{PSf}$, (d) $3 \mathrm{NH}_{2}-\mathrm{RHO} / \mathrm{PSf}$, (e) $4 \mathrm{NH}_{2}-\mathrm{RHO} / \mathrm{PSf}$, and (f) $5 \mathrm{NH}_{2}-\mathrm{RHO} / \mathrm{PSf} \mathrm{MMMs}$.

\subsection{Spectroscopic Analysis}

\subsubsection{Comparison of Zeolite $\mathrm{RHO}$ and $\mathrm{NH}_{2}-\mathrm{RHO}$}

Figure 5 depicts the FTIR spectra of zeolite $\mathrm{RHO}$ and $\mathrm{NH}_{2}$ - $\mathrm{RHO}$. The observed FTIR spectra differences between zeolite $\mathrm{RHO}$ and $\mathrm{NH}_{2}-\mathrm{RHO}$ are also indicated in Figure 5 . As can be seen in Figure 5a for zeolite RHO, the FTIR spectrum portrayed a strong absorption peak in the range of $1250-950 \mathrm{~cm}^{-1}$, which corresponds to $\mathrm{Si}-\mathrm{O}$ and $\mathrm{Al}-\mathrm{O}$ tetrahedra asymmetrical stretching vibration in the zeolite RHO particle [29,37]. Intense absorption peaks located in the range of $3650-3200 \mathrm{~cm}^{-1}$ and $1640 \mathrm{~cm}^{-1}$ indicated the presence of $\mathrm{O}-\mathrm{H}$ stretching of adsorbed water molecules and $\mathrm{O}-\mathrm{H}$ bending of lattice water in the zeolite RHO sample [38]. Besides, a low intensity absorption peak identified at $794 \mathrm{~cm}^{-1}$ can be connected to $\mathrm{Si}-\mathrm{Al}-\mathrm{O}$ symmetrical stretching vibration. The characteristic absorption peak of double eight-ring external linkage in zeolite RHO was revealed at $588 \mathrm{~cm}^{-1}$ and $634 \mathrm{~cm}^{-1}[29,38]$. 


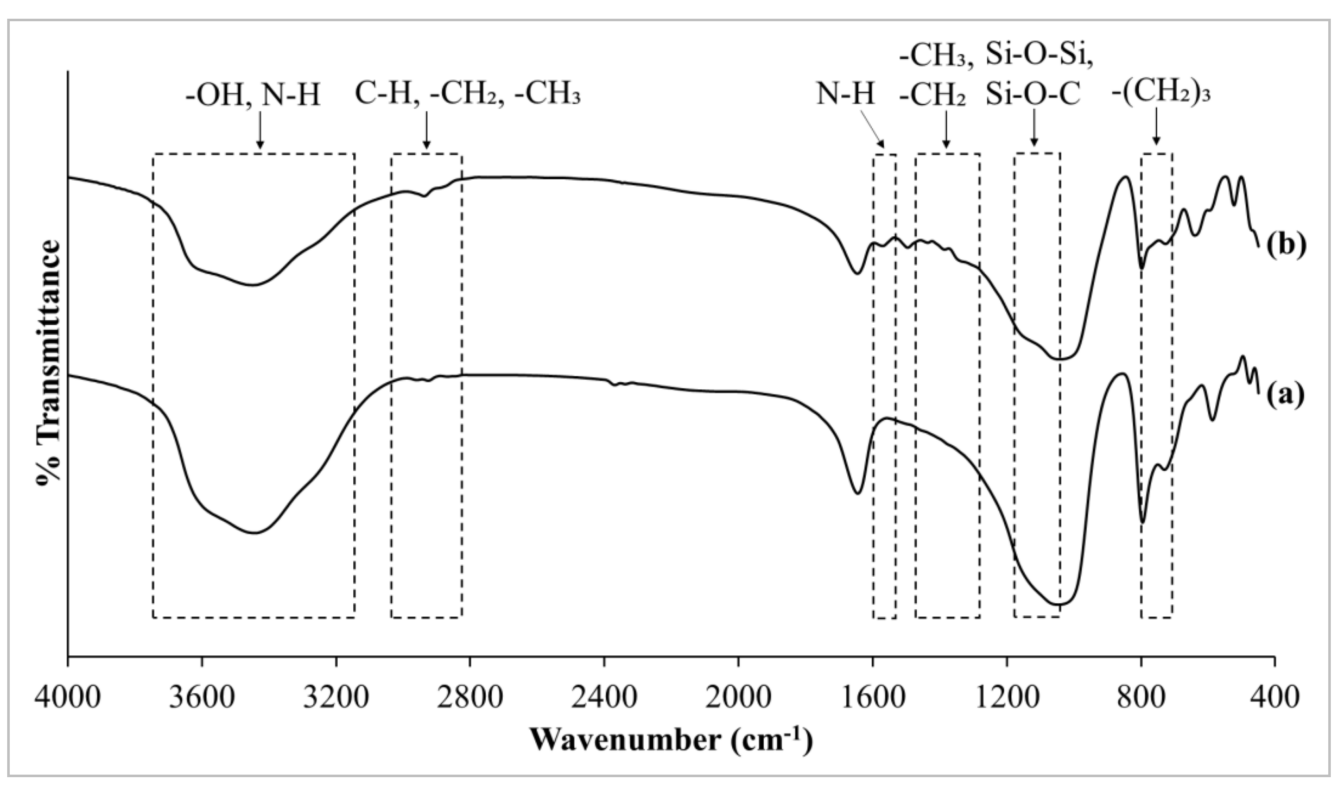

Figure 5. FTIR spectra of (a) zeolite $\mathrm{RHO}$ and (b) zeolite $\mathrm{NH}_{2}-\mathrm{RHO}$.

As observed from Figure $5 \mathrm{~b}$ for $\mathrm{NH}_{2}-\mathrm{RHO}$, the absorption peak ranging from $3650-3200 \mathrm{~cm}^{-1}$ showed an increasing broadness compared to that of zeolite RHO. This can be ascribed to the presence of $\mathrm{N}-\mathrm{H}$ stretching vibration of primary amine from APTES, which was overlapping with $\mathrm{O}-\mathrm{H}$ stretching vibrations of hydroxyl group in the same frequency spectra range [34]. Moreover, a slight increase at the absorption peak of about $2937 \mathrm{~cm}^{-1}$ was attributed to aliphatic $\mathrm{C}-\mathrm{H},-\mathrm{CH}_{2},-\mathrm{CH}_{3}$ stretching vibrations due to the introduction of APTES onto zeolite RHO [28]. This is in agreement with Ismail et al. [28] where APTES was used to modify the surface of zeolite $4 \mathrm{~A}$. The zeolite $\mathrm{NH}_{2}-\mathrm{RHO}$ also displayed the increased intensity of absorption peaks within the range of $1500-1300 \mathrm{~cm}^{-1}$, which represents the $\mathrm{Si}-\mathrm{CH}_{2}$ - and $\mathrm{Si}-\mathrm{CH}_{3}$ stretching vibrations of silane groups. Likewise, the observed increment in broadness of absorption peaks ranging from $780-726 \mathrm{~cm}^{-1}$ for zeolite $\mathrm{NH}_{2}-\mathrm{RHO}$ was connected to $-\left(\mathrm{CH}_{2}\right)_{3}-$ rotations and vibrations [14]. These proved that the silane coupling agent, APTES was adhered to the surface of zeolite RHO. An analogous observation was reported by Amooghin et al. [15] in the surface modification of zeolite NaY by APDEMS.

According to Ismail et al. [28], the physical and chemical adsorption reactions of silane coupling agents can be further verified by the silanol groups on the zeolite surface. There is a weak, broad overlapped absorption peak at about $1097 \mathrm{~cm}^{-1}$, related to asymmetric stretching of $\mathrm{Si}-\mathrm{O}-\mathrm{Si}$ with $\mathrm{Si}-\mathrm{O}-\mathrm{C}$ stretching vibration, which originates from non-bridging $\mathrm{O}-\mathrm{H}$ stretching vibration. Hydrogen bonding was created between the $\mathrm{O}$ atom of an $\mathrm{OH}$ group bonded to the $\mathrm{Si}$ atom of zeolite $\mathrm{RHO}$ surface and $\mathrm{H}$ atom of an $\mathrm{OH}$ group bonded to the $\mathrm{Si}$ atom of the APTES molecule [28]. In addition, the N-H bending vibration of primary amine was also noticeable in Figure $5 \mathrm{~b}$ with the additional absorption peak at the frequency of about $1562 \mathrm{~cm}^{-1}$ for zeolite $\mathrm{NH}_{2}-\mathrm{RHO}$, but it was absent in the spectrum of zeolite RHO (Figure 5a) [34]. In other words, the silane modification on zeolite RHO surface had successfully taken place.

\subsubsection{Comparison of Pristine PSf Membrane and MMMs}

Figure 6 shows the FTIR-ATR spectra of pristine PSf membrane, $\mathrm{RHO} / \mathrm{PSf}$ and $\mathrm{NH}_{2-}$ RHO/PSf MMMs. Based on Figure 6a, FTIR spectrum of pristine PSf membrane exhibited characteristic absorption peaks at about $1295 \mathrm{~cm}^{-1}$ and $1323 \mathrm{~cm}^{-1}$, corresponding to the presence of $\mathrm{O}=\mathrm{S}=\mathrm{O}$ stretching vibration. The absorption peaks of $\mathrm{C}-\mathrm{H}$ stretching and bending vibrations of aliphatic rings were identified at about $2967 \mathrm{~cm}^{-1}$ and $1364 \mathrm{~cm}^{-1}$, respectively. $-\left(\mathrm{CH}_{2}\right)_{3}-$ rotations and vibrations were also visible at the absorption peaks 
ranging from $3070-2850 \mathrm{~cm}^{-1}$ and $770-630 \mathrm{~cm}^{-1}$, respectively [14,39]. In the meantime, stretching vibration of $\mathrm{C}=\mathrm{C}$ due to benzene ring appeared as a medium intensity absorption peak at about $1485 \mathrm{~cm}^{-1}$ and $1584 \mathrm{~cm}^{-1}[14,15,40]$. There is a strong intensity absorption peak at about $1235 \mathrm{~cm}^{-1}$, which was ascribed to $\mathrm{C}-\mathrm{O}$ stretching vibration where the oxygen atom is bonded to two phenyl groups. An analogous observation was also reported by Muntha et al. [40] in the fabrication of PSf/zeolite 3A MMMs.

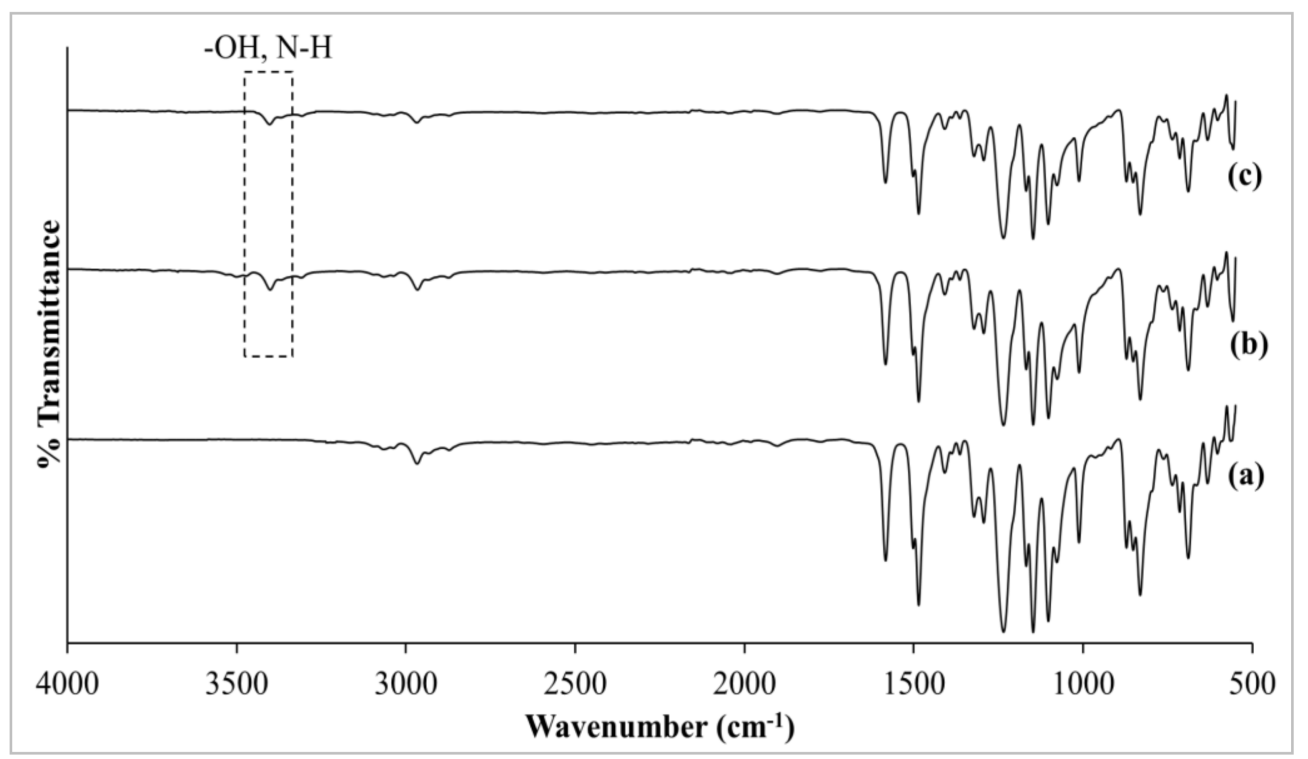

Figure 6. FTIR spectra of (a) pristine PSf membrane, (b) $5 \mathrm{RHO} / \mathrm{PSf}$, and (c) $5 \mathrm{NH}_{2}-\mathrm{RHO} / \mathrm{PSf} \mathrm{MMMs}$.

The fabricated MMMs with zeolite $\mathrm{RHO}$ and $\mathrm{NH}_{2}-\mathrm{RHO}$ portrayed similar and comparable FTIR spectra to pristine PSf membranes, as displayed in Figure 6b,c. Intense absorption peaks in the range of $1080-960 \mathrm{~cm}^{-1}$ were attributed to the asymmetrical stretching vibration of $\mathrm{Si}-\mathrm{O}$ and $\mathrm{Al}-\mathrm{O}$ tetrahedral in the zeolite $\mathrm{RHO}$ and $\mathrm{NH}_{2}-\mathrm{RHO}$ [41]. However, both $\mathrm{RHO} / \mathrm{PSf}$ and $\mathrm{NH}_{2}-\mathrm{RHO} / \mathrm{PSf}$ MMMs revealed higher shoulder band within the range of $1075-1020 \mathrm{~cm}^{-1}$ compared with pristine PSf membranes. Furthermore, an overlapped peak at about $1012 \mathrm{~cm}^{-1}$ was represented by Si-O-C stretching vibration [14]. A similar observation was reported by Junaidi et al. [14] where a SAPO-34 zeolite was incorporated into a PSf matrix.

It is evident that the characteristic sulfone peaks were maintained but the peak intensities slightly decreased by incorporating zeolite $\mathrm{RHO}$ and $\mathrm{NH}_{2}-\mathrm{RHO}$ into the PSf matrix. On the other hand, an additional absorption peak at about $3402 \mathrm{~cm}^{-1}$ for $\mathrm{N}-\mathrm{H}$ stretching vibration of primary amine was observed in Figure 6, indicating the presence of APTES on the zeolite surface. The relative intensities were weakened due to superimposing frequency spectra of O-H stretching vibration of zeolite RHO in the range of $3600-3000 \mathrm{~cm}^{-1}$ [34].

\subsection{Thermal Analysis}

\subsubsection{Comparison of Zeolite $\mathrm{RHO}$ and $\mathrm{NH}_{2}-\mathrm{RHO}$}

Figure 7 illustrates the TGA-DTG thermogram for zeolite $\mathrm{RHO}$ and $\mathrm{NH}_{2}-\mathrm{RHO}$. In fact, the synthesized zeolite $\mathrm{RHO}$ and $\mathrm{NH}_{2}-\mathrm{RHO}$ possessed high thermal stability upon heating from 30 to $800{ }^{\circ} \mathrm{C}$. As visualized in Figure 7, both zeolite $\mathrm{RHO}$ and $\mathrm{NH}_{2}-\mathrm{RHO}$ manifested a sharp weight loss from about 30 to $250{ }^{\circ} \mathrm{C}$ ascribing to the desorption and removal of physically adsorbed water within zeolite RHO pores [42]. At $800{ }^{\circ} \mathrm{C}$, the total weight loss for zeolite $\mathrm{NH}_{2}-\mathrm{RHO}$ was $29.9 \%$, as compared to $16.5 \%$ weight loss for zeolite RHO. This situation can be attributed to the additional decomposition of silane coupling agent modified on the surface of zeolite RHO, which took place from about 350 to $550{ }^{\circ} \mathrm{C}$ [43]. 


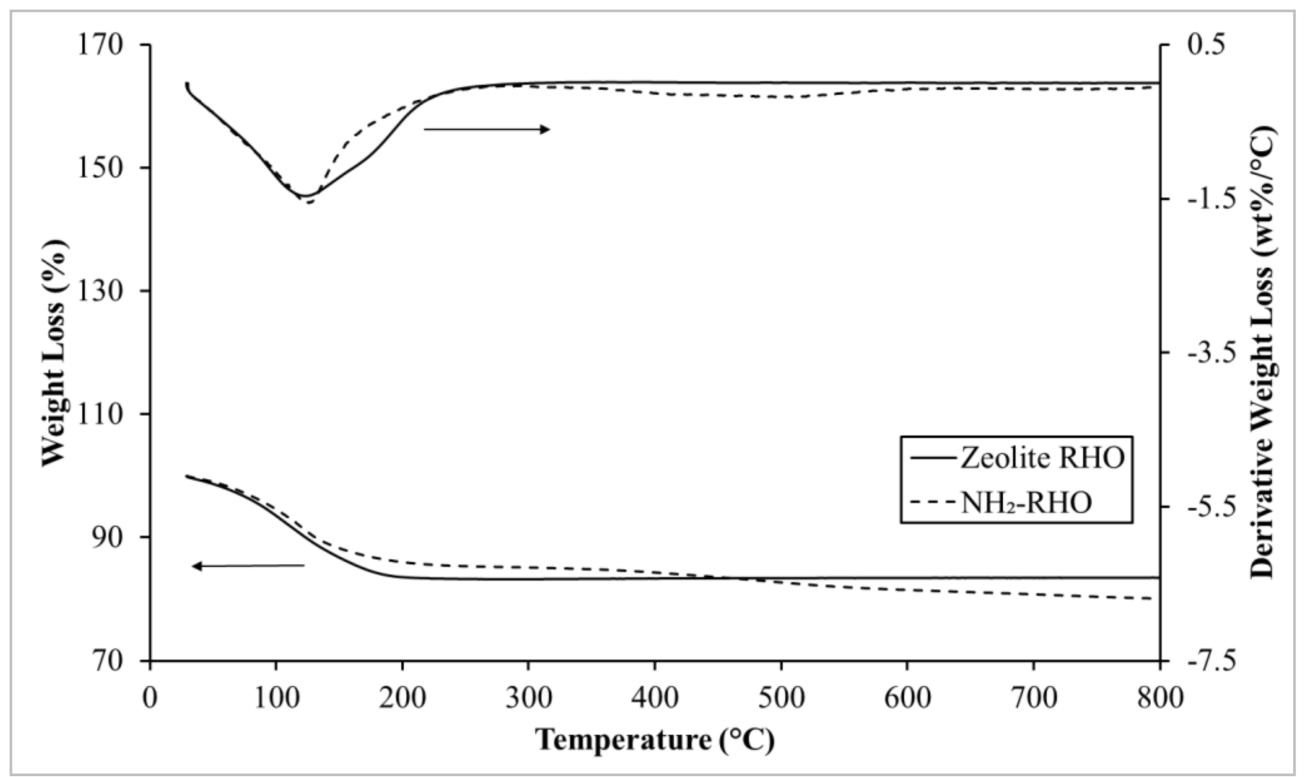

Figure 7. TGA-DTG thermograms of zeolite $\mathrm{RHO}$ and $\mathrm{NH}_{2}-\mathrm{RHO}$.

\subsubsection{Comparison of Pristine PSf Membrane and MMMs}

Thermal stability of pristine PSf membrane and MMMs were investigated via TGADTG analysis, and the results are shown in Figures 8 and 9 while Table 2 depicts the decomposition temperature of the membranes. Referring to the TGA and DTG thermograms in Figures 8 and 9, several observations could be drawn from the incorporation of zeolite $\mathrm{RHO}$ and $\mathrm{NH}_{2}-\mathrm{RHO}$ in PSf polymer matrix. Firstly, the membranes experienced two obvious stages of weight loss, where the first stage occurred at about 30 to $250{ }^{\circ} \mathrm{C}$, indicating desorption of moisture and solvent residue during fabrication [44]. Subsequently, the second stage occurred above $460^{\circ} \mathrm{C}$, which ascribed to thermal decomposition of the main polymer chain [15]. The decomposition temperature, $T_{d}$ for pristine PSf was observed at $532.86^{\circ} \mathrm{C}$ and it shifted slightly to higher values for the MMMs incorporated with $5 \mathrm{wt} \%$ of zeolite $\mathrm{RHO}$ or $\mathrm{NH}_{2}-\mathrm{RHO}$, as illustrated in Figure 9.

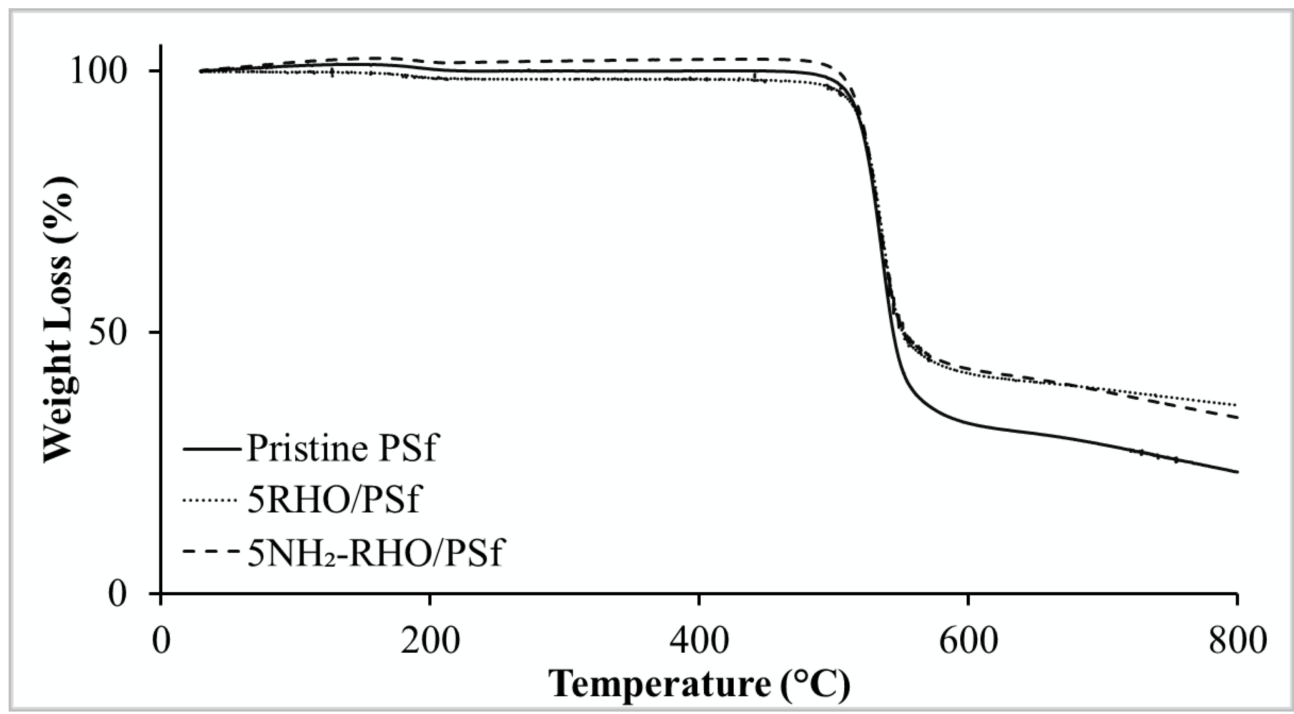

Figure 8. TGA thermograms of pristine PSf membrane, 5RHO/PSf, and 5 $\mathrm{NH}_{2}-\mathrm{RHO} / \mathrm{PSf} \mathrm{MMMs}$. 


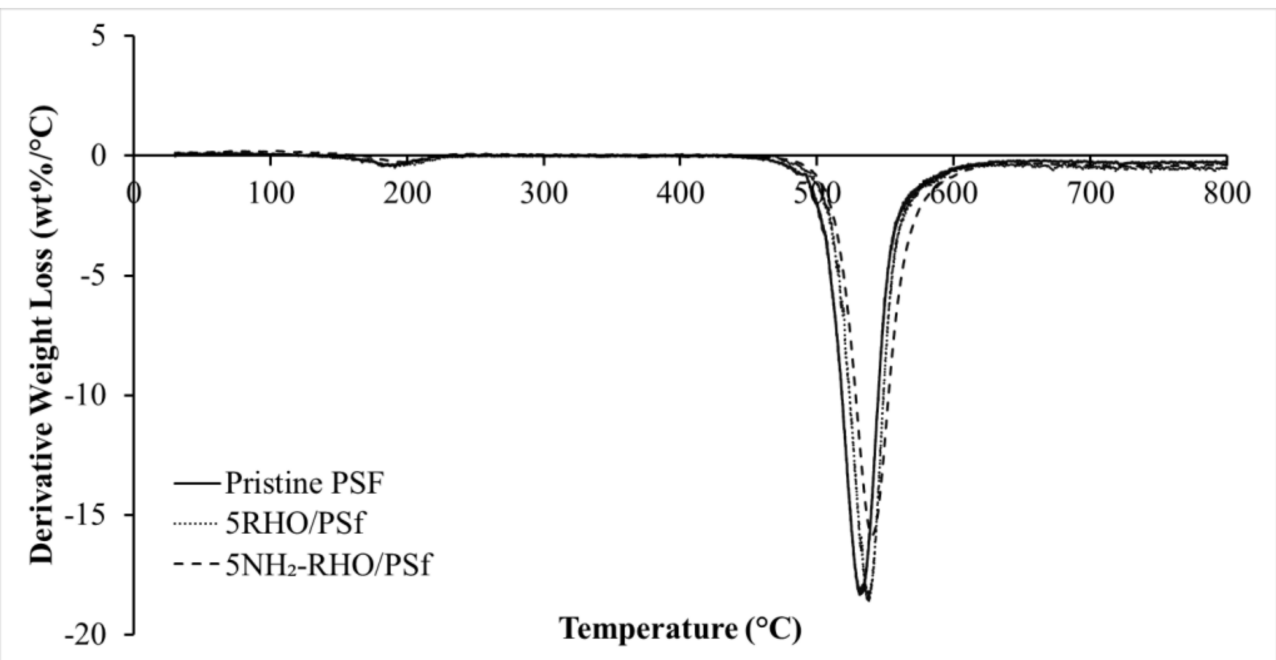

Figure 9. DTG thermograms of pristine PSf membrane, 5RHO/PSf, and $5 \mathrm{NH}_{2}-\mathrm{RHO} / \mathrm{PSf} \mathrm{MMMs}$.

Table 2. Decomposition temperature of pristine PSf membrane and MMMs.

\begin{tabular}{cc}
\hline Sample & Decomposition Temperature, $\boldsymbol{T}_{\boldsymbol{d}}\left({ }^{\circ} \mathbf{C}\right)$ \\
\hline Pristine PSf & 532.86 \\
1RHO/PSf & 536.46 \\
$2 \mathrm{RHO} / \mathrm{PSf}$ & 537.02 \\
3RHO/PSf & 537.22 \\
$4 \mathrm{RHO} / \mathrm{PSf}$ & 537.63 \\
$5 \mathrm{RHO} / \mathrm{PSf}$ & 538.22 \\
$1 \mathrm{NH}_{2}-\mathrm{RHO} / \mathrm{PSf}$ & 539.16 \\
$2 \mathrm{NH}_{2}-\mathrm{RHO} / \mathrm{PSf}$ & 539.29 \\
$3 \mathrm{NH}_{2}-\mathrm{RHO} / \mathrm{PSf}$ & 539.87 \\
$4 \mathrm{NH}_{2}-\mathrm{RHO} / \mathrm{PSf}$ & 540.53 \\
$5 \mathrm{NH}_{2}-\mathrm{RHO} / \mathrm{PSf}$ & 540.70 \\
\hline
\end{tabular}

In order to explore the effect of zeolite on the thermal stability of the PSf matrix, different loading of zeolite $\mathrm{RHO}$ or $\mathrm{NH}_{2}-\mathrm{RHO}$ were added to the PSf matrix. It was observed from Table 2 where the $T_{d}$ trend of MMMs increased gradually with increasing loading of zeolite $\mathrm{RHO}$ or $\mathrm{NH}_{2}-\mathrm{RHO}$. This indicates that the thermal stability of MMMs was enhanced gradually with increasing loading of zeolite $\mathrm{RHO}$ or $\mathrm{NH}_{2}-\mathrm{RHO}$ in the MMMs [45]. Generally, increasing zeolite filler loading in the polymer matrix would enhance the interaction between polymer and filler. Strong hydrogen bond and covalent bond formed between zeolite $\mathrm{RHO}$ or $\mathrm{NH}_{2}-\mathrm{RHO}$ with PSf matrix confine the thermal motion of polymer chain and hence, higher energy would be required for the segmentation and decomposition of polymer chains [46].

\subsection{Morphological Analysis}

FESEM was performed to provide a visualization of the membrane structure and morphology. Figure 10 portrays the cross-sectional FESEM image of the pristine PSf membrane and the MMMs incorporated with zeolite RHO. Upon incorporation of 1 to $5 \mathrm{wt} \%$ of zeolite RHO particles into PSf polymer matrix, the appearance of zeolite RHO particles across PSf polymer matrix were observed. There were few empty cavities representing zeolite RHO particles being cleaved away when the MMMs were fractured with liquid nitrogen. It is observed that the membrane morphology was smoother when low loading of zeolite RHO was incorporated into the membrane. However, the formation of interfacial voids was detected between zeolite RHO particles and polymer matrix in the MMMs incorporated with higher loading of zeolite RHO as shown in Figure 10, which might be due to partial incompatibility between PSf polymer matrix and zeolite RHO [47]. The effect of partial 
incompatibility between PSf polymer matrix and zeolite RHO was greater at higher loading of zeolite RHO. An analogous phenomenon was reported by Huang et al. [47] when zeolite beta was incorporated into PSf matrix. As zeolite RHO loading increased beyond $4 \mathrm{wt} \%$, obvious zeolite RHO particle agglomeration and severe interfacial voids at PSf/zeolite RHO interfacial region can be observed in Figure 10. Similarly, the formation of interfacial voids and filler agglomeration, especially at high zeolite loadings, has also been reported for several zeolite-filled MMMs by Amooghin et al. [46], Huang et al. [47], and Li et al. [48].
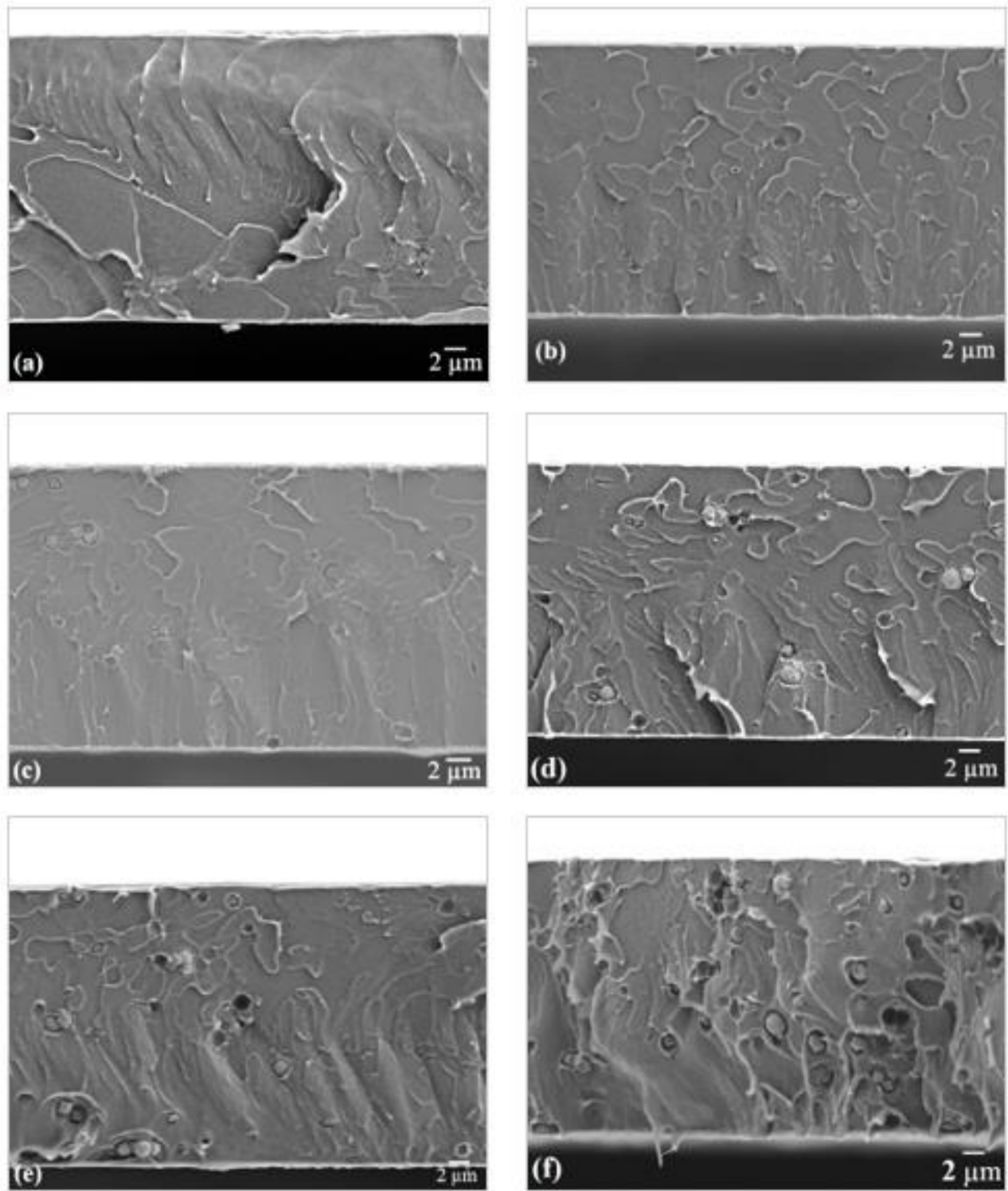

Figure 10. Cross sectional FESEM images of (a) pristine PSf membrane, (b) 1RHO/PSf, (c) 2RHO/PSf, (d) $3 \mathrm{RHO} / \mathrm{PSf}$, (e) $4 \mathrm{RHO} / \mathrm{PSf}$, and (f) $5 \mathrm{RHO} / \mathrm{PSf}$ MMMs.

Cross sectional FESEM images of the fabricated MMMs with different $\mathrm{NH}_{2}-\mathrm{RHO}$ loadings were illustrated in Figure 11. Upon addition of 1 to $3 \mathrm{wt} \%$ of $\mathrm{NH}_{2}-\mathrm{RHO}$ particles to the MMMs, no obvious interfacial voids between $\mathrm{NH}_{2}-\mathrm{RHO}$ particles and PSf matrix can be observed. In the presence of APTES, interfacial strength between PSf and $\mathrm{NH}_{2}-\mathrm{RHO}$ was enhanced significantly, resulting in stronger polymer/inorganic filler adhesion. The silane groups of APTES are able to bind with the hydroxyl groups on the zeolite RHO surface, while the amino group can bind with the sulfone group in PSf, forming hydrogen and covalent bonds between PSf and $\mathrm{NH}_{2}-\mathrm{RHO}$ particles [20]. Similar observations were found by Amooghin et al. [15] for APDEMS-modified zeolites with Matrimid. 

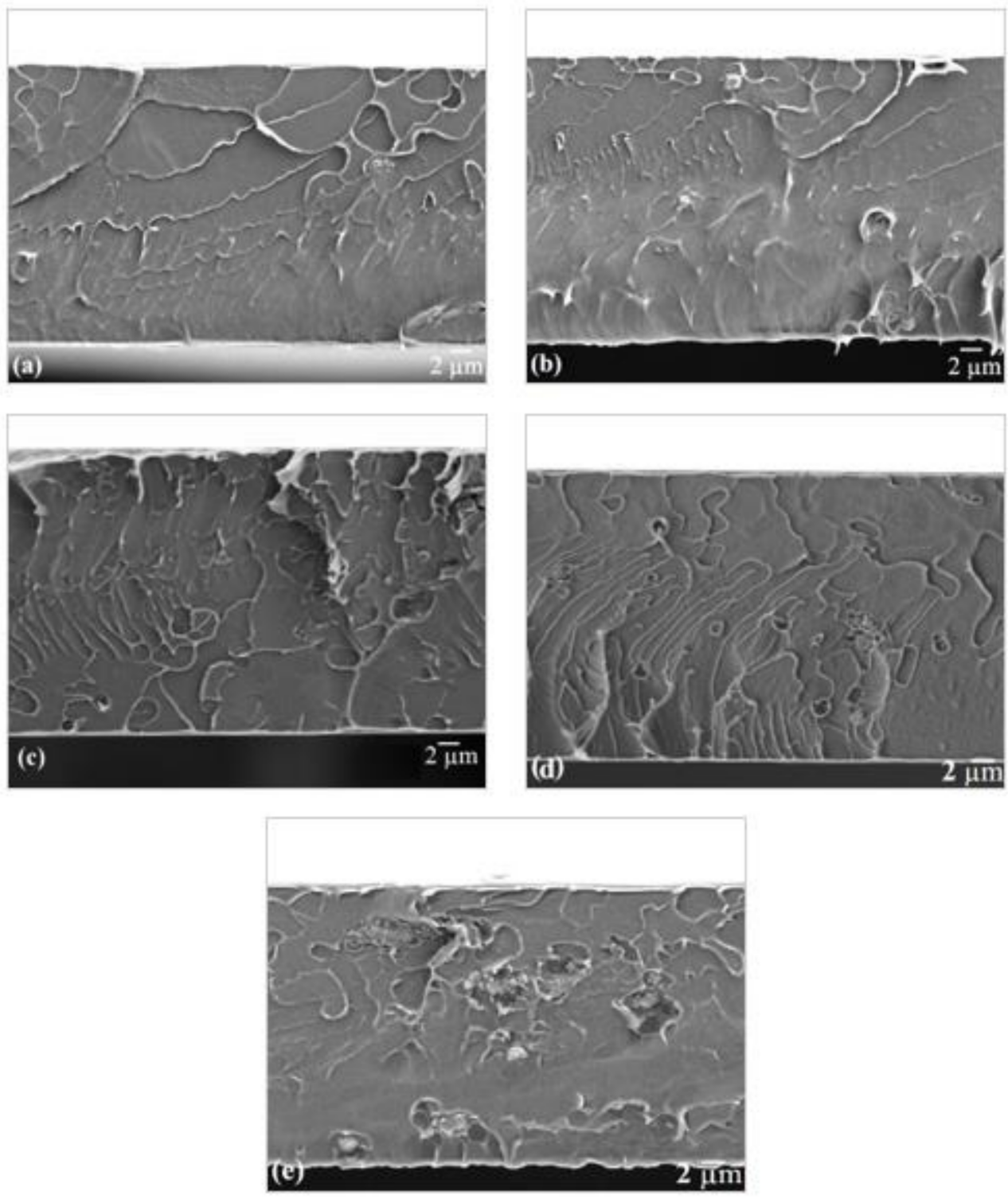

Figure 11. Cross sectional FESEM images of (a) $1 \mathrm{NH}_{2}-\mathrm{RHO} / \mathrm{PSf}$, (b) $2 \mathrm{NH}_{2}-\mathrm{RHO} / \mathrm{PSf}$, (c) $3 \mathrm{NH}_{2}-$ $\mathrm{RHO} / \mathrm{PSf},(\mathbf{d}) 4 \mathrm{NH}_{2}-\mathrm{RHO} / \mathrm{PSf}$, and (e) $5 \mathrm{NH}_{2}-\mathrm{RHO} / \mathrm{PSf}$ MMMs.

\subsection{Gas Permeation and Separation Evalution}

\subsubsection{Effect of Zeolite RHO Loadings}

Figure 12 displays the gas permeation and separation performance of pristine PSf membrane and RHO/PSf MMMs. $\mathrm{CO}_{2}$ permeability and ideal $\mathrm{CO}_{2} / \mathrm{CH}_{4}$ selectivity of pristine PSf membrane in this study were comparable with those reported in the literature $[49,50]$. When $1 \mathrm{wt} \%$ of zeolite RHO was incorporated into PSf based MMMs, the $\mathrm{CO}_{2}$ permeability and ideal $\mathrm{CO}_{2} / \mathrm{CH}_{4}$ selectivity were slightly increased by $4.2 \%$ and $2.7 \%$, respectively, compared to that of the pristine PSf membrane. The slight enhancement of ideal $\mathrm{CO}_{2} / \mathrm{CH}_{4}$ selectivity could be contributed by the molecular sieving effect of small pore zeolite $\mathrm{RHO}$ incorporated into the $\mathrm{MMMs} . \mathrm{CO}_{2}$ gas molecules with smaller kinetic diameter could permeate through $\mathrm{RHO} / \mathrm{PSf}$ MMMs with less resistance compared to $\mathrm{CH}_{4}$ gas molecules [11,12]. In addition, the polar character of zeolite RHO has greater affinity towards $\mathrm{CO}_{2}$ [51], leading to the slight improvement in ideal $\mathrm{CO}_{2} / \mathrm{CH}_{4}$ selectivity when $1 \mathrm{wt} \%$ of zeolite RHO was incorporated into PSf based MMMs in the current study. 


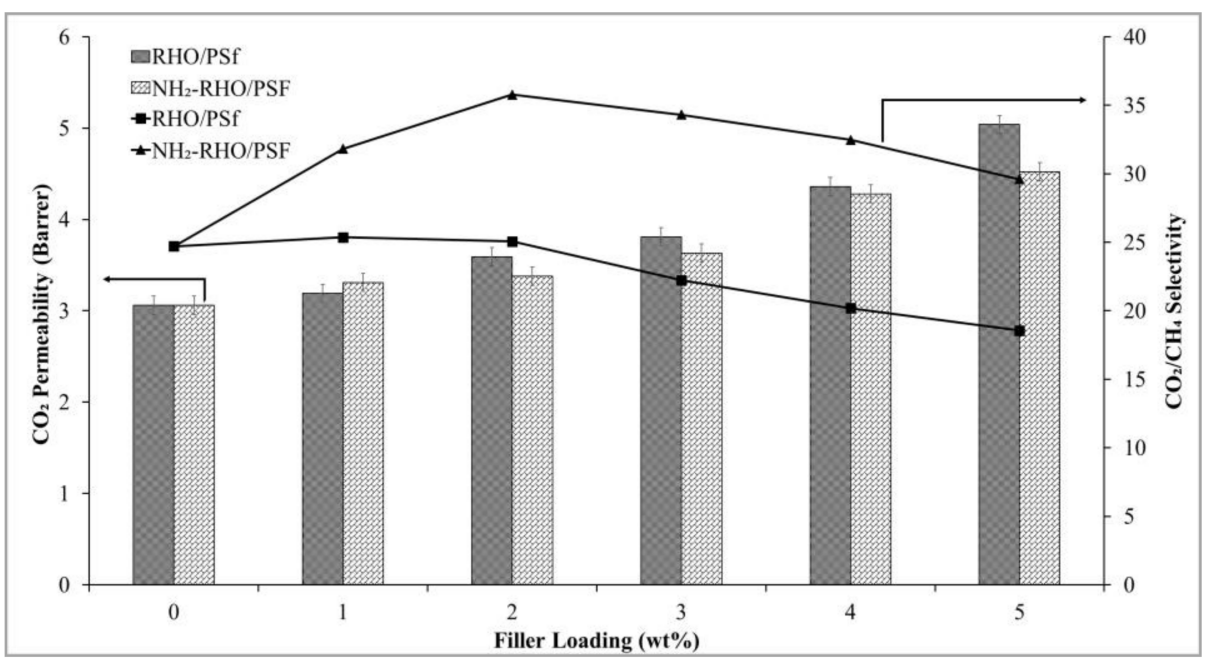

Figure 12. Gas permeation and separation performance of pristine PSf membrane and MMMs.

However, increasing zeolite $\mathrm{RHO}$ loading beyond $1 \mathrm{wt} \%$ has resulted in the increase in $\mathrm{CO}_{2}$ permeability and increase in $\mathrm{CH}_{4}$ permeability but decrease in the ideal $\mathrm{CO}_{2} / \mathrm{CH}_{4}$ selectivity. This might be due to weak interaction between PSf matrix and zeolite RHO, the effect of which was greater at higher zeolite loading levels. Incorporation of low loading of $1 \mathrm{wt} \%$ zeolite RHO into PSf did not obviously affect the membrane morphology. When the zeolite RHO loading was higher than $1 \mathrm{wt} \%$, the effect of weak interactions between the PSf matrix and zeolite RHO started to take place and the interfacial voids started to form at the PSf/zeolite RHO interface, plausibly produced a gaseous bypass between PSf polymer chain and incorporated zeolite RHO particles [47]. The free volume between polymer chain and zeolite RHO increased, causing a leaky interface with the presence of non-selective interfacial voids at the PSf/zeolite RHO interfacial region [27]. These interfacial voids are non-selective as it allows gas molecules to pass through the voids with less resistance instead of passing through zeolite pores [52]. Hence, the $\mathrm{CO}_{2}$ permeability increased but the ideal $\mathrm{CO}_{2} / \mathrm{CH}_{4}$ selectivity was sacrificed when zeolite $\mathrm{RHO}$ loading in the MMMs increased from 1 to $5 \mathrm{wt} \%$.

\subsubsection{Effect of Zeolite $\mathrm{NH}_{2}-\mathrm{RHO}$}

Gas permeation and separation performance of $\mathrm{NH}_{2}-\mathrm{RHO} / \mathrm{PSf}$ MMMs is depicted in Figure 12. Based on Figure 12, $\mathrm{CO}_{2}$ permeability of $\mathrm{NH}_{2}-\mathrm{RHO} / \mathrm{PSf}$ MMMs showed an increasing trend with increasing $\mathrm{NH}_{2}-\mathrm{RHO}$ loading in the MMMs. A significant increase of $45 \%$ in ideal $\mathrm{CO}_{2} / \mathrm{CH}_{4}$ selectivity was achieved when $2 \mathrm{wt} \%$ of $\mathrm{NH}_{2}-\mathrm{RHO}$ was incorporated into the MMMs compared to the pristine PSf membrane. Besides, $\mathrm{NH}_{2}-\mathrm{RHO} / \mathrm{PSf}$ MMMs with $2 \mathrm{wt} \%$ of $\mathrm{NH}_{2}-\mathrm{RHO}$ content exhibited about $43 \%$ higher ideal $\mathrm{CO}_{2} / \mathrm{CH}_{4}$ selectivity compared to that of RHO/PSf MMMs with $2 \mathrm{wt} \%$ of zeolite RHO loading. The enhanced ideal $\mathrm{CO}_{2} / \mathrm{CH}_{4}$ selectivity of $\mathrm{NH}_{2}-\mathrm{RHO} / \mathrm{PSf} \mathrm{MMMs}$ was due to the molecular sieving effect by the small pore zeolite $\mathrm{NH}_{2}-\mathrm{RHO}$ incorporated into the MMMs. In addition, APTES modified on zeolite RHO strengthened the interfacial interaction between PSf and $\mathrm{NH}_{2}-\mathrm{RHO}$ particles as well as significantly reduced the formation of interfacial voids, producing MMMs with enhanced morphology [22]. Therefore, the increase in ideal $\mathrm{CO}_{2} / \mathrm{CH}_{4}$ selectivity with the incorporation of $2 \mathrm{wt} \%$ of $\mathrm{NH}_{2}-\mathrm{RHO}$ into the MMMs was contributed by the small pore size of $\mathrm{NH}_{2}-\mathrm{RHO}$, as well as enhanced MMMs morphology. These results were in line with FESEM observations as shown in Figure 11 where no obvious interfacial void can be seen at the PSf $/ \mathrm{NH}_{2}-\mathrm{RHO}$ interface for incorporation of $\mathrm{NH}_{2}-\mathrm{RHO}$ particles of up to $3 \mathrm{wt} \%$ loading. 


\section{Conclusions}

MMMs incorporated with zeolite $\mathrm{RHO}$ and $\mathrm{NH}_{2}-\mathrm{RHO}$ particles have been successfully fabricated in the current study. The incorporation of $\mathrm{NH}_{2}-\mathrm{RHO}$ particles has contributed to the enhanced thermal stability of MMMs as indicated in the TGA-DTG analysis. Furthermore, by incorporating $1-3 \mathrm{wt} \%$ zeolite $\mathrm{NH}_{2}-\mathrm{RHO}$ into the PSf matrix, MMMs without interfacial voids were successfully fabricated due to the enhancement in polymer/filler interfacial strength. Consequently, the $\mathrm{NH}_{2}-\mathrm{RHO} / \mathrm{PSf}$ MMMs displayed higher ideal $\mathrm{CO}_{2} / \mathrm{CH}_{4}$ selectivity compared to $\mathrm{RHO} / \mathrm{PSf}$ MMMs. A significant increase of $45 \%$ in ideal $\mathrm{CO}_{2} / \mathrm{CH}_{4}$ selectivity was achieved when $2 \mathrm{wt} \%$ of $\mathrm{NH}_{2}-\mathrm{RHO}$ was incorporated into the MMMs compared to pristine PSf membrane. The silane coupling agent (APTES) played an important role in strengthening the interfacial interaction between PSf and $\mathrm{NH}_{2}-\mathrm{RHO}$ particles and thereby significantly enhanced the ideal $\mathrm{CO}_{2} / \mathrm{CH}_{4}$ selectivity of the MMMs. The results obtained in this work contribute to the advancement of knowledge of the fabrication of membranes. Future research could be focused on investigation of the membranes in other configurations with higher membrane surface areas.

Author Contributions: Conceptualization, T.L.C., Y.F.Y., and Y.T.O.; formal analysis, T.Y.S.N., T.L.C., Y.F.Y., and Z.A.J.; investigation, T.Y.S.N.; methodology, T.Y.S.N. and T.L.C.; supervision, T.L.C. and Y.F.Y.; writing—original draft, T.Y.S.N.; writing—review and editing, L.D.A., T.L.C., Y.F.Y., S.C.L., and C.-D.H. All authors have read and agreed to the published version of the manuscript.

Funding: This research was funded by the Fundamental Research Grant Scheme (FRGS) Ref: FRGS/1/2020/TK0/UTP/02/28 (Cost center: 015MA0-123) from the Ministry of Higher Education Malaysia (MOHE) and YUTP-Fundamental Research Grant (Cost center: 015LC0-258).

Institutional Review Board Statement: Not applicable.

Informed Consent Statement: Not applicable.

Data Availability Statement: Not applicable.

Acknowledgments: This research work was supported by the Fundamental Research Grant Scheme (FRGS) Ref: FRGS/1/2020/TK0/UTP/02/28 (Cost center: 015MA0-123) from the Ministry of Higher Education Malaysia (MOHE) and YUTP-Fundamental Research Grant (Cost center: 015LC0-258). The author would also like to acknowledge support from Universiti Teknologi PETRONAS (UTP), Institute of Contaminant Management, UTP and $\mathrm{CO}_{2}$ Research Centre (CO2RES), UTP.

Conflicts of Interest: The authors declare no conflict of interest. The funders had no role in the design of the study; in the collection, analyses, or interpretation of data; in the writing of the manuscript; or in the decision to publish the results.

\section{References}

1. Rezakazemi, M.; Amooghin, A.E.; Montazer-Rahmati, M.M.; Ismail, A.F.; Matsuura, T. State-of-the-art membrane based CO 2 separation using mixed matrix membranes (MMMs): An overview on current status and future directions. Prog. Polym. Sci. 2014, 39, 817-886. [CrossRef]

2. Bernardo, P.; Drioli, E.; Golemme, G. Membrane gas separation: A review/state of the art. Ind. Eng. Chem. Res. 2009, 48, 4638-4663. [CrossRef]

3. Forster, L.; D'Agostino, C.; Llosa-Tanco, M.A.; Spallina, V.; Brencio, C.; Gallucci, F.; Lindley, M.; Haigh, S.J.; Pacheco-Tanaka, D.A. Tailoring pore structure and surface chemistry of microporous Alumina-Carbon Molecular Sieve Membranes (Al-CMSMs) by altering carbonization temperature for optimal gas separation performance: An investigation using low-field NMR relaxation measurements. Chem. Eng. J. 2021, 424, 129313. [CrossRef]

4. Robeson, L.M. The upper bound revisited. J. Membr. Sci. 2008, 320, 390-400. [CrossRef]

5. Tavolaro, A.; Drioli, E. Zeolite membranes. Adv. Mater. 1999, 11, 975-996. [CrossRef]

6. Dong, G.; Li, H.; Chen, V. Challenges and opportunities for mixed-matrix membranes for gas separation. J. Mater. Chem. A 2013, 1, 4610-4630. [CrossRef]

7. Noble, R.D. Perspectives on mixed matrix membranes. J. Membr. Sci. 2011, 378, 393-397. [CrossRef]

8. Zimmerman, C.M.; Singh, A.; Koros, W.J. Tailoring mixed matrix composite membranes for gas separations. J. Membr. Sci. 1997, 137, 145-154. [CrossRef] 
9. Corbin, D.R.; Abrams, L.; Jones, G.A.; Eddy, M.M.; Harrison, W.T.A.; Stucky, G.D.; Cox, D.E. Flexibility of the zeolite RHO framework: In situ x-ray and neutron powder structural characterization of divalent cation-exchanged zeolite RHO. J. Am. Chem. Soc. 1990, 112, 4821-4830. [CrossRef]

10. Burton, A. Zeolites: Porous architectures. Nat. Mater. 2003, 2, 438-440. [CrossRef]

11. Garces, L.; Makwana, V.; Hincapie, B.; Sacco, A.; Suib, S. Selective N, N-methylation of aniline over cocrystallized zeolites RHO and zeolite X (FAU) and over Linde type L (Sr, K-LTL). J. Catal. 2003, 217, 107-116. [CrossRef]

12. Atalay-Oral, C.; Tatlier, M. Characterization of mixed matrix membranes by adsorption and fractal analysis. Sep. Sci. Technol. 2019, 54, 2323-2333. [CrossRef]

13. Chen, X.Y.; Nik, O.G.; Rodrigue, D.; Kaliaguine, S. Mixed matrix membranes of aminosilanes grafted FAU/EMT zeolite and cross-linked polyimide for $\mathrm{CO}_{2} / \mathrm{CH}_{4}$ separation. Polymer 2012, 53, 3269-3280. [CrossRef]

14. Junaidi, M.; Khoo, C.; Leo, C.; Ahmad, A. The effects of solvents on the modification of SAPO-34 zeolite using 3-aminopropyl trimethoxy silane for the preparation of asymmetric polysulfone mixed matrix membrane in the application of $\mathrm{CO}_{2}$ separation. Microporous Mesoporous Mater. 2014, 192, 52-59. [CrossRef]

15. Amooghin, A.E.; Omidkhah, M.; Kargari, A. The effects of aminosilane grafting on NaY zeolite-Matrimid ${ }^{\circledR} 5218$ mixed matrix membranes for CO2/CH4 separation. J. Membr. Sci. 2015, 490, 364-379. [CrossRef]

16. Nik, O.G.; Chen, X.Y.; Kaliaguine, S. Amine-functionalized zeolite FAU/EMT-polyimide mixed matrix membranes for $\mathrm{CO}_{2} / \mathrm{CH}_{4}$ separation. J. Membr. Sci. 2011, 379, 468-478. [CrossRef]

17. Khan, A.L.; Cano-Odena, A.; Gutiérrez, B.; Minguillón, C.; Vankelecom, I.F. Hydrogen separation and purification using polysulfone acrylate-zeolite mixed matrix membranes. J. Membr. Sci. 2010, 350, 340-346. [CrossRef]

18. Liu, Y.-L.; Su, Y.-H.; Lee, K.-R.; Lai, J.-Y. Crosslinked organic-inorganic hybrid chitosan membranes for pervaporation dehydration of isopropanol-water mixtures with a long-term stability. J. Membr. Sci. 2005, 251, 233-238. [CrossRef]

19. Plueddemann, E.P. Coupling Agent Compositions. United States Patent US4689085A, 12 January 1988.

20. Zhou, H.; Su, Y.; Chen, X.; Yi, S.; Wan, Y. Modification of silicalite-1 by vinyltrimethoxysilane (VTMS) and preparation of silicalite-1 filled polydimethylsiloxane (PDMS) hybrid pervaporation membranes. Sep. Purif. Technol. 2010, 75, 286-294. [CrossRef]

21. Moore, T.T.; Koros, W.J. Sorption in Zeolites Modified for Use in Organic- Inorganic Hybrid Membranes. Ind. Eng. Chem. Res. 2008, 47, 591-598. [CrossRef]

22. Husain, S.; Koros, W.J. Mixed matrix hollow fiber membranes made with modified HSSZ-13 zeolite in polyetherimide polymer matrix for gas separation. J. Membr. Sci. 2007, 288, 195-207. [CrossRef]

23. Vrancken, K.; Possemiers, K.; Van Der Voort, P.; Vansant, E.F. Surface modification of silica gels with aminoorganosilanes. Colloids Surf. A 1995, 98, 235-241. [CrossRef]

24. Flinn, D.; Guzonas, D.; Yoon, R.-H. Characterization of silica surfaces hydrophobized by octadecyltrichlorosilane. Colloids Surf. A 1994, 87, 163-176. [CrossRef]

25. Plueddemann, E.P. Nature of adhesion through silane coupling agents. In Silane Coupling Agents; Plueddemann, E.P., Ed.; Springer: New York, NY, USA, 1982; pp. 111-139.

26. Pechar, T.W.; Tsapatsis, M.; Marand, E.; Davis, R. Preparation and characterization of a glassy fluorinated polyimide zeolite-mixed matrix membrane. Desalination 2002, 146, 3-9. [CrossRef]

27. Pechar, T.W.; Kim, S.; Vaughan, B.; Marand, E.; Tsapatsis, M.; Jeong, H.K.; Cornelius, C.J. Fabrication and characterization of polyimide-zeolite L mixed matrix membranes for gas separations. J. Membr. Sci. 2006, 277, 195-202. [CrossRef]

28. Ismail, A.; Kusworo, T.; Mustafa, A. Enhanced gas permeation performance of polyethersulfone mixed matrix hollow fiber membranes using novel Dynasylan Ameo silane agent. J. Membr. Sci. 2008, 319, 306-312. [CrossRef]

29. Ng, T.Y.S.; Chew, T.L.; Yeong, Y.F.; Jawad, Z.A.; Ho, C.-D. Zeolite RHO Synthesis Accelerated by Ultrasonic Irradiation Treatment. Sci. Rep. 2019, 9, 1-11. [CrossRef]

30. Abedini, R.; Omidkhah, M.; Dorosti, F. Effect of Amine-Functionalized MIL-53 Metal Organic Frameworks on the Performance of Poly (4-methyl-1-pentyne) Membrane in $\mathrm{CO}_{2} / \mathrm{CH}_{4}$ Separation Gas Mixture. Iran. J. Polym. Sci. Technol. 2015, $28,131-147$.

31. Hillock, A.M.; Miller, S.J.; Koros, W.J. Crosslinked mixed matrix membranes for the purification of natural gas: Effects of sieve surface modification. J. Membr. Sci. 2008, 314, 193-199. [CrossRef]

32. Liu, X.; Zhang, X.; Chen, Z.; Tan, X. Hydrothermal synthesis of zeolite Rho using methylcellulose as the space-confinement additive. Ceram. Int. 2013, 39, 5453-5458. [CrossRef]

33. Kim, J.H.; Lee, Y.M. Gas permeation properties of poly (amide-6-b-ethylene oxide)-silica hybrid membranes. J. Membr. Sci. 2001, 193, 209-225. [CrossRef]

34. Sanaeepur, H.; Kargari, A.; Nasernejad, B. Aminosilane-functionalization of a nanoporous Y-type zeolite for application in a cellulose acetate based mixed matrix membrane for $\mathrm{CO}_{2}$ separation. RSC Adv. 2014, 4, 63966-63976. [CrossRef]

35. Ionita, M.; Vasile, E.; Crica, L.E.; Voicu, S.I.; Pandele, A.M.; Dinescu, S.; Predoiu, L.; Galateanu, B.; Hermenean, A.; Costache, M. Synthesis, characterization and in vitro studies of polysulfone/graphene oxide composite membranes. Compos. B 2015, 72, 108-115. [CrossRef]

36. Ahmad, J.; Hägg, M.-B. Development of matrimid/zeolite 4A mixed matrix membranes using low boiling point solvent. Sep. Purif. Technol. 2013, 115, 190-197. [CrossRef]

37. Charkhi, A.; Kazemeini, M.; Ahmadi, S.J.; Kazemian, H. Fabrication of granulated NaY zeolite nanoparticles using a new method and study the adsorption properties. Powder Technol. 2012, 231, 1-6. [CrossRef] 
38. Flank, W.H. Properties of Synthesized, Ion-Exchanged, and Stabilized Zeolite Rho. ACS Symp. Ser. 1977, 40, 43-52.

39. Kiadehi, A.D.; Rahimpour, A.; Jahanshahi, M.; Ghoreyshi, A.A. Novel carbon nano-fibers (CNF)/polysulfone (PSf) mixed matrix membranes for gas separation. J. Ind. Eng. Chem. 2015, 22, 199-207. [CrossRef]

40. Muntha, S.T.; Siddiq, M.; Kausar, A.; Khan, A. Mixed matrix membranes of polysulfone/polyimide reinforced with modified zeolite based filler: Preparation, properties and application. Chin. J. Polym. Sci. 2018, 36, 65-77. [CrossRef]

41. Leo, C.; Kamil, N.A.; Junaidi, M.U.M.; Kamal, S.; Ahmad, A.L. The potential of SAPO-44 zeolite filler in fouling mitigation of polysulfone ultrafiltration membrane. Sep. Purif. Technol. 2013, 103, 84-91. [CrossRef]

42. Chatelain, T.; Patarin, J.; Fousson, E.; Soulard, M.; Guth, J.; Schulz, P. Synthesis and characterization of high-silica zeolite RHO prepared in the presence of 18-crown-6 ether as organic template. Microporous Mater. 1995, 4, 231-238. [CrossRef]

43. Khemakhem, S.; Ben Amar, R. Modification of Tunisian clay membrane surface by silane grafting: Application for desalination with Air Gap Membrane Distillation process. Colloids Surf. A Physicochem. Eng. Asp. 2011, 387, 79-85. [CrossRef]

44. Hosseinzadeh Beiragh, H.; Omidkhah, M.; Abedini, R.; Khosravi, T.; Pakseresht, S. Synthesis and characterization of poly (ether-block-amide) mixed matrix membranes incorporated by nanoporous ZSM-5 particles for $\mathrm{CO}_{2} / \mathrm{CH}_{4}$ separation. Asia-Pac. J. Chem. Eng. 2016, 11, 522-532. [CrossRef]

45. Castro-Muñoz, R.; Fíla, V. Progress on Incorporating Zeolites in Matrimid®5218 Mixed Matrix Membranes towards Gas Separation. Membranes 2018, 8, 30. [CrossRef] [PubMed]

46. Amooghin, A.E.; Omidkhah, M.; Kargari, A. Enhanced CO2 transport properties of membranes by embedding nano-porous zeolite particles into Matrimid ${ }^{\circ} 5218$ matrix. RSC Adv. 2014, 5, 8552-8565. [CrossRef]

47. Huang, Z.; Su, J.-F.; Guo, Y.-H.; Su, X.-Q.; Teng, L.-J. Synthesis of well-crystallized zeolite beta at large scale and its incorporation into polysulfone matrix for gas separation. Chem. Eng. Commun. 2009, 196, 969-986. [CrossRef]

48. Li, Y.; Guan, H.-M.; Chung, T.-S.; Kulprathipanja, S. Effects of novel silane modification of zeolite surface on polymer chain rigidification and partial pore blockage in polyethersulfone (PES)-zeolite A mixed matrix membranes. J. Membr. Sci. 2006, 275, 17-28. [CrossRef]

49. Kim, S.; Marand, E.; Ida, J.; Guliants, V.V. Polysulfone and mesoporous molecular sieve MCM-48 mixed matrix membranes for gas separation. Chem. Mater. 2006, 18, 1149-1155. [CrossRef]

50. Ahn, J.; Chung, W.-J.; Pinnau, I.; Guiver, M.D. Polysulfone/silica nanoparticle mixed-matrix membranes for gas separation. J. Membr. Sci. 2008, 314, 123-133. [CrossRef]

51. Palomino, M.; Corma, A.; Jorda, J.L.; Rey, F.; Valencia, S. Zeolite Rho: A highly selective adsorbent for $\mathrm{CO}_{2} / \mathrm{CH}_{4}$ separation induced by a structural phase modification. Chem. Commun. 2012, 48, 215-217. [CrossRef]

52. Mahajan, R.; Burns, R.; Schaeffer, M.; Koros, W.J. Challenges in forming successful mixed matrix membranes with rigid polymeric materials. J. Appl. Polym. Sci. 2002, 86, 881-890. [CrossRef] 